NASA/TM-2007-214630

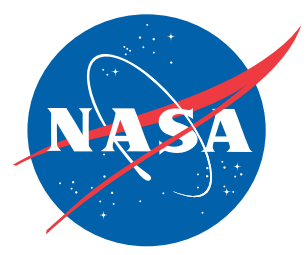

\title{
The X-43A Six Degree of Freedom Monte Carlo Analysis
}

Ethan Baumann, Catherine Bahm, and Brian Strovers NASA Dryden Flight Research Center

Edwards, California

Roger Beck

Analytical Mechanics Associates, Inc.

Hampton, Virginia

Michael Richard

Rockwell Collins

Cedar Rapids, Iowa

\section{December 2007}


NASA STI Program ... in Profile

Since its founding, NASA has been dedicated to the advancement of aeronautics and space science. The NASA scientific and technical information (STI) program plays a key part in helping NASA maintain this important role.

The NASA STI program is operated under the auspices of the Agency Chief Information Officer. It collects, organizes, provides for archiving, and disseminates NASA's STI. The NASA STI program provides access to the NASA Aeronautics and Space Database and its public interface, the NASA Technical Report Server, thus providing one of the largest collections of aeronautical and space science STI in the world. Results are published in both non-NASA channels and by NASA in the NASA STI Report Series, which includes the following report types:

- $\quad$ TECHNICAL PUBLICATION. Reports of completed research or a major significant phase of research that present the results of NASA programs and include extensive data or theoretical analysis. Includes compilations of significant scientific and technical data and information deemed to be of continuing reference value. NASA counterpart of peerreviewed formal professional papers but has less stringent limitations on manuscript length and extent of graphic presentations.

- TECHNICAL MEMORANDUM. Scientific and technical findings that are preliminary or of specialized interest, e.g., quick release reports, working papers, and bibliographies that contain minimal annotation. Does not contain extensive analysis.

- $\quad$ CONTRACTOR REPORT. Scientific and technical findings by NASA-sponsored contractors and grantees.
- CONFERENCE PUBLICATION. Collected papers from scientific and technical conferences, symposia, seminars, or other meetings sponsored or cosponsored by NASA.

- SPECIAL PUBLICATION. Scientific, technical, or historical information from NASA programs, projects, and missions, often concerned with subjects having substantial public interest.

- TECHNICAL TRANSLATION. Englishlanguage translations of foreign scientific and technical material pertinent to NASA's mission.

Specialized services also include creating custom thesauri, building customized databases, and organizing and publishing research results.

For more information about the NASA STI program, see the following:

- $\quad$ Access the NASA STI program home page at http://www.sti.nasa.gov

- $\quad$ E-mail your question via the Internet to help@sti.nasa.gov

- Fax your question to the NASA STI Help Desk at (301) 621-0134

- Phone the NASA STI Help Desk at (301) 621-0390

- Write to: NASA STI Help Desk NASA Center for AeroSpace Information 7115 Standard Drive Hanover, MD 21076-1320 
NASA/TM-2007-214630

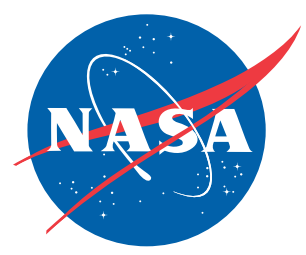

\section{The X-43A Six Degree of Freedom Monte Carlo Analysis}

Ethan Baumann, Catherine Bahm, and Brian Strovers NASA Dryden Flight Research Center

Edwards, California

Roger Beck

Analytical Mechanics Associates, Inc.

Hampton, Virginia

Michael Richard

Rockwell Collins

Cedar Rapids, Iowa

National Aeronautics and

Space Administration

Dryden Flight Research Center

Edwards, California 93523-0273

\section{December 2007}




\section{NOTICE}

Use of trade names or names of manufacturers in this document does not constitute an official endorsement of such products or manufacturers, either expressed or implied, by the National Aeronautics and Space Administration.

Available from:

NASA Center for AeroSpace Information

7115 Standard Drive

Hanover, MD 21076-1320

(301) 621-0390 


\begin{abstract}
This report provides an overview of the Hyper-X research vehicle Monte Carlo analysis conducted with the six-degree-of-freedom simulation. The methodology and model uncertainties used for the Monte Carlo analysis are presented as permitted. In addition, the process used to select hardware validation test cases from the Monte Carlo data is described. The preflight Monte Carlo analysis indicated that the X-43A control system was robust to the preflight uncertainties and provided the Hyper-X project an important indication that the vehicle would likely be successful in accomplishing the mission objectives. The X-43A in-flight performance is compared to the preflight Monte Carlo predictions and shown to exceed the Monte Carlo bounds in several instances. Possible modeling shortfalls are presented that may account for these discrepancies. The flight control laws and guidance algorithms were robust enough as a result of the preflight Monte Carlo analysis that the unexpected in-flight performance did not have undue consequences. Modeling and Monte Carlo analysis lessons learned are presented.
\end{abstract}

\title{
NOMENCLATURE
}

$\begin{array}{ll}\text { alpha } & \text { angle of attack } \\ \text { AIL } & \text { aircraft-in-the-loop } \\ \text { AMW } & \text { all-moving wing } \\ \text { Avg } & \text { average } \\ \text { CA } & \text { axial force coefficient } \\ \text { CA bias } & \text { axial force bias } \\ \text { CFD } & \text { computational fluid dynamics } \\ \text { CG } & \text { center of gravity } \\ \text { Cl } & \text { roll moment coefficient } \\ \text { Cl bias } & \text { roll moment bias } \\ \text { Clp } & \text { roll moment caused by roll rate } \\ \text { Cm } & \text { pitch moment coefficient } \\ \text { Cm bias } & \text { pitch moment bias } \\ \text { Cmo } & \text { pitching moment at zero degree angle of attack } \\ \text { Cmq } & \text { pitch moment caused by pitch rate } \\ \mathrm{Cn} & \text { yaw moment coefficient } \\ \mathrm{Cn} \text { bias } & \text { yaw moment coefficient bias } \\ \mathrm{Cnp} & \text { yaw moment caused by roll rate } \\ \mathrm{Cnr} & \text { roll moment caused by yaw rate } \\ \mathrm{CP} & \text { pressure coefficient } \\ \mathrm{CY} & \text { side force coefficient }\end{array}$




$\begin{array}{ll}\text { CY bias } & \text { side force bias } \\ \text { CZ } & \text { normal force coefficient } \\ \text { CZ bias } & \text { normal force bias } \\ \text { DFRC } & \text { Dryden Flight Research Center } \\ \text { FADS } & \text { flush airdata sensing } \\ \text { FMU } & \text { flight management unit } \\ \text { G } & \text { gravitational acceleration } \\ \text { GNC } & \text { guidance, navigation, and control } \\ \text { GRAM } & \text { Global Reference Atmospheric Model } \\ \text { h } & \text { altitude } \\ \text { HIL } & \text { hardware-in-the-loop } \\ \text { HXLV } & \text { Hyper-X Launch Vehicle } \\ \text { HXRV } & \text { Hyper-X Research Vehicle } \\ \text { INS } & \text { inertial navigation system } \\ \text { kft } & \text { thousands of feet } \\ \text { MCAT } & \text { Monte Carlo analysis tool } \\ \text { PID } & \text { parameter identification } \\ \text { PPT } & \text { pressure port transducer } \\ \text { SepSim } & \text { detailed simulation of separation dynamics } \\ \text { SIM } & \text { simulation } \\ \text { UA } & \text { unavailable } \\ \text { 6-DOF } & \text { six degree-of-freedom } \\ \text { O } & \text { drag dispersion } \\ & \end{array}$

\section{INTRODUCTION}

Before the initial flight-testing of a new aircraft, there is always some uncertainty as to how the vehicle will actually perform. These uncertainties increase when the vehicle is a unique aircraft flying in a seldom-explored flight regime. One such unique vehicle is the X-43A, which was the first unmanned vehicle to fly at hypersonic speeds with a scramjet engine. A Monte Carlo analysis was conducted to predict and bound the performance of the X-43A, hereafter referred to as the Hyper-X research vehicle (HXRV). Monte Carlo analysis is a useful and commonly used technique to assess system performance to predicted parameter variations by means of a stochastic process. The analysis consists of independent and random variations of all applicable model inputs and parameters within the estimated uncertainty bounds. Random combinations of input uncertainties can produce different, and potentially worse, results than deterministically varying a single uncertainty or set of uncertainties. Monte Carlo analysis consists of making multiple simulation runs, with each run containing a unique set of parameter variations, and analyzing the 
results. A close examination of these simulation runs provides insight into the system performance and characteristics. Monte Carlo analysis forces the flight control laws and guidance algorithms to be robust to a large range of uncertainties. Stress testing past the modeled uncertainty range can provide an assessment of the vehicle robustness to the unknown unknowns present in every flight research program. This type of analysis is particularly useful for unmanned vehicles where there is no pilot in the loop acting as an adaptive controller.

The purpose of this report is to provide an overview of the HXRV Monte Carlo analysis tools, present the uncertainties used as part of the Monte Carlo analysis (as permitted), and discuss the results of the Monte Carlo analysis. In addition, limited comparisons between simulation and flight data are presented with an emphasis placed on highlighting modeling shortfalls. The selection process for the subset of runs used during hardware validation testing is described, and lessons learned and observations concerning the Monte Carlo analysis are presented.

\section{PROJECT DESCRIPTION}

The goal of the NASA Hyper-X program was to demonstrate an advanced, airframeintegrated, airbreathing, hypersonic propulsion system in flight, thus validating the supporting tools and technologies (ref. 1). The program sought to design, build, and flight-test a series of three small, autonomous, scramjet-powered Hyper-X research vehicles (HXRV), designated X-43A, at Mach 7 and 10. The vehicles were dropped from the NASA Dryden Flight Research Center (DFRC) B-52B airplane (The Boeing Company, Chicago, Illinois) over the Pacific Ocean and rocket-boosted to its test point. Prior to flight test, the Hyper-X program conducted extensive ground testing, simulation, and analysis. In support of these activities, a high-fidelity six degreeof-freedom (6-DOF) nonlinear simulation of the research vehicle was developed at DFRC. The research vehicle simulation was meant to accurately model the vehicle dynamics after separation from the Hyper-X launch vehicle (HXLV), including the engine test and controlled flight down to the water. Many of the simulation models included uncertainties or dispersions that were used in the Monte Carlo analysis.

\section{The Hyper-X Research Vehicle (HXRV) Description}

As shown in figure 1, the HXRV was an unmanned autonomous vehicle that measured approximately $12 \mathrm{ft}$ long and $5 \mathrm{ft}$ wide, and weighed approximately $3000 \mathrm{lb}$. The scramjet engine was attached to the underside of the HXRV and contained a cowl door on the leading edge of the engine that was used to control airflow through the engine. The HXRV had four control surface effectors: a left and right all-moving wing (AMW) and twin rudders. The HXRV was fitted to the front end of the Hyper-X launch vehicle (HXLV), a modified Pegasus ${ }^{\circledR}$ (Orbital Sciences Corporation, Chandler, Arizona) rocket used to boost the HXRV to the desired test condition. The combination of the HXRV and HXLV was known as the X-43A stack, and was carried to the launch point under the wing of the NASA DFRC NB-52B airplane, ship number 008. 


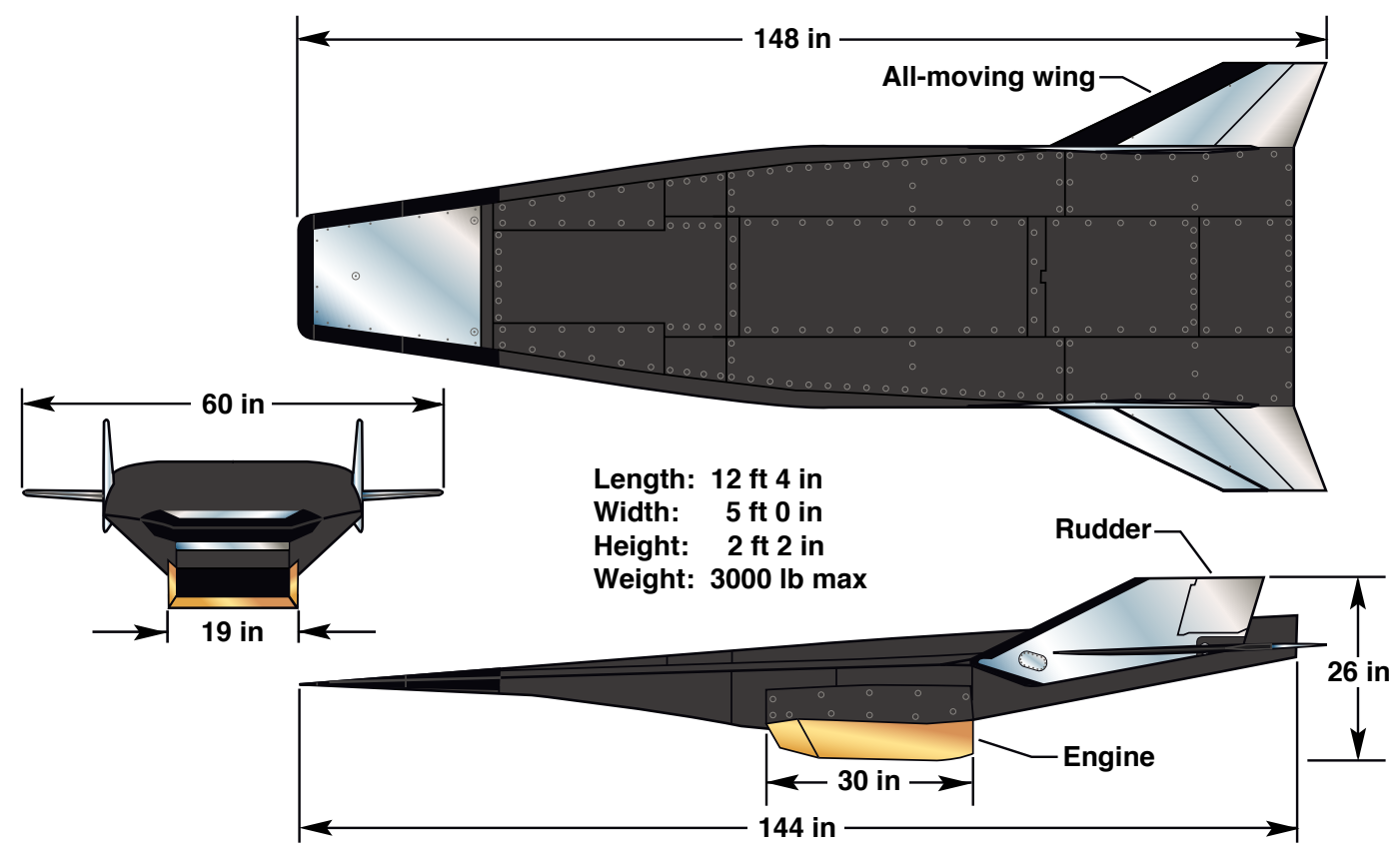

070264

Figure 1. The X-43A 3-View.

\section{Flight Test of the Hyper-X Research Vehicle}

Three HXRVs were built for the Hyper-X program. Two of the vehicles were intended for missions at Mach 7, and one vehicle was intended for a mission at Mach 10. The HXRVs collectively received the designation of X-43A. All three vehicles have the same outer mold line; the primary difference among the vehicles is the internal engine flowpaths. Flight 1 was intended to reach Mach 7 and was attempted on June 2, 2001. The HXLV lost control shortly after launch, resulting in the loss of both the HXLV and HXRV (ref. 2). During Flight 2, flown to Mach 6.8 on March 27, 2004, the HXRV successfully demonstrated the in-flight operation of the scramjet (ref. 3). All of the goals for that mission were achieved, including positive acceleration of the vehicle by the scramjet. The third and final flight was flown to Mach 9.6 on November 16, 2004 (ref. 4). During both successful missions, the HXRV was in a controlled autonomous flight from the point of separation to splashdown in the Pacific Ocean.

\section{The Hyper-X Research Vehicle Mission Description}

The HXRV mission timelines were similar for Flight 2 and Flight 3. The principal difference between the two flights is the higher Mach number attained during Flight 3, which resulted in a correspondingly longer descent trajectory. Figure 2 shows an overview of the HXRV mission. The launch, scramjet experiment, and descent portions of the mission were conducted off the coast of southern California. For both missions, the HXLV propelled the X-43A stack to a separation altitude of approximately 100,000 ft and a dynamic pressure of approximately $1000 \mathrm{psf}$. The HXRV separated at Mach 6.9 during Flight 2 and at Mach 9.7 during Flight 3. Several seconds after 
separation, the primary experiment, which consisted of the scramjet engine test, was conducted. The primary experiment lasted approximately $45 \mathrm{~s}$ for Flight 2 and $30 \mathrm{~s}$ for Flight 3 . After the completion of the primary experiment, the cowl door was closed and a recovery maneuver was initiated to arrest the vehicle descent and dynamic pressure buildup. After the descent was arrested, an unpowered trajectory was flown to a splashdown into the Pacific Ocean. During the descent, a series of parameter identification (PID) maneuvers were performed at every integer Mach number down to Mach 2 (refs. 5, 6). These maneuvers began at Mach 5 for Flight 2 and at Mach 8 for Flight 3.

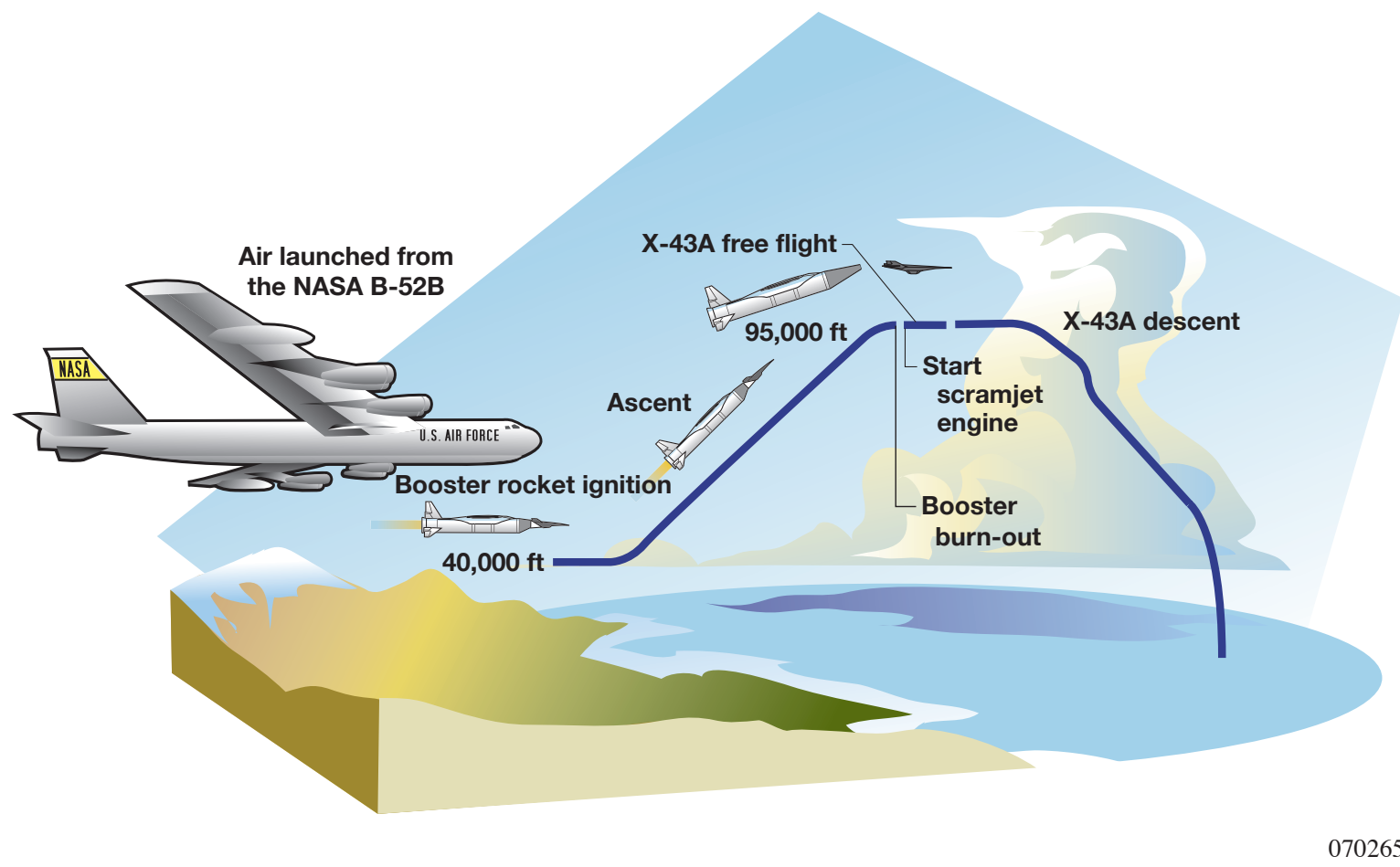

Figure 2. Hyper-X flight trajectory.

\section{MONTE CARLO ANALYSIS OVERVIEW}

The DFRC 6-DOF nonlinear simulation of the HXRV was used in conjunction with a series of Matlab ${ }^{\circledR}$ (The MathWorks, Natick, Massachusetts) scripts to conduct the Monte Carlo analysis. The primary objectives of the Monte Carlo uncertainty analysis were to assess vehicle stability in the presence of modeling and measurement uncertainties, the flight conditions during the engine test, the unpowered descent trajectory, and the controlled flight impact area. Statistical information from the Monte Carlo analysis was examined, but was not the primary product. The project was most concerned with assessing the vehicle performance and the expected flight envelope in the presence of the expected model uncertainties. This performance assessment turned out to be largely Boolean in nature. The vehicle performance was either acceptable or not. Software performance, including the flight control laws, guidance, and scramjet controller (ref. 7) was a part of this assessment. The Monte Carlo objectives were achieved by conducting many thousands of simulation runs, with 
each run having a random combination of modeling uncertainties. To gain a greater understanding of the relationships between the dispersions and their effects on the trajectory, data were correlated to determine combinations of factors that most influenced the performance of the aircraft. A secondary objective consisted of using the uncertainty analysis data to find a limited set of runs that could be used for thorough validation testing of the flight hardware and software systems.

\section{The Hyper-X Research Vehicle Monte Carlo Analysis Tool (MCAT)}

A Monte Carlo analysis tool (MCAT) was developed to stress the vehicle system with predicted uncertainties. The HXRV MCAT tests the vehicle performance in the presence of random and unique sets of input parameter uncertainties. The MCAT consists of a set of Matlab ${ }^{\circledast} \mathrm{M}$-files that are used as controlling scripts to drive the nonlinear simulation with various dispersions, analyze the results, save the data, and plot the data for further analysis. Matlab ${ }^{\circledR}$ M-files are used to automate the process of generating the thousands of simulation scripts.

An execution of the MCAT consists of a large number of simulation runs with the first run being nominal and the rest containing different combinations of uncertainties.

Manipulation and storage of the Monte Carlo results presented numerous challenges. Several gigabytes of data were produced by each set of simulation runs. The analysis tools run in the Matlab $^{\circledR}$ workspace were incapable of handling a complete Monte Carlo dataset. The large amount of data resulted in the partitioning of the Monte Carlo data into multiple .mat files. A separate .mat file was generated for each simulation output variable and this file contained data from all of the simulation runs. To minimize the amount of data stored from a Monte Carlo analysis, trade-offs were made between the rate at which the data were saved and the number of signals saved for short-term and long-term storage. The parameters of greatest interest were saved at $100 \mathrm{~Hz}$ during the engine experiment phase. During other phases of the simulated missions, data were saved at $10 \mathrm{~Hz}$. Relatively slowly-varying parameters, such as altitude, Mach, latitude, and longitude were stored at $1 \mathrm{~Hz}$. Table 1 shows the Monte Carlo parameters saved at each rate. Parameters of greatest interest were retained indefinitely, whereas less important data was deleted after a week to allow storage space for the next set of Monte Carlo results.

Figure 3 is a flowchart graphically representing the stochastic MCAT process. The inputs of each simulation run, including the desired uncertainties, are defined in an input file that is called a simulation input script. The MCAT generates the simulation input scripts and details the number of simulation runs. The MCAT then uses the simulation input scripts to run the simulation in a batch mode a number of times specified by the MCAT and saves a subset of the simulation parameters that are recorded for later analysis. The simulation input scripts were deleted after each Monte Carlo run to save space. The simulation output data of each of these saved parameters are collected from each simulation run into separate matrices (one for each parameter). The data matrices are then stored for future analysis and plotting. 


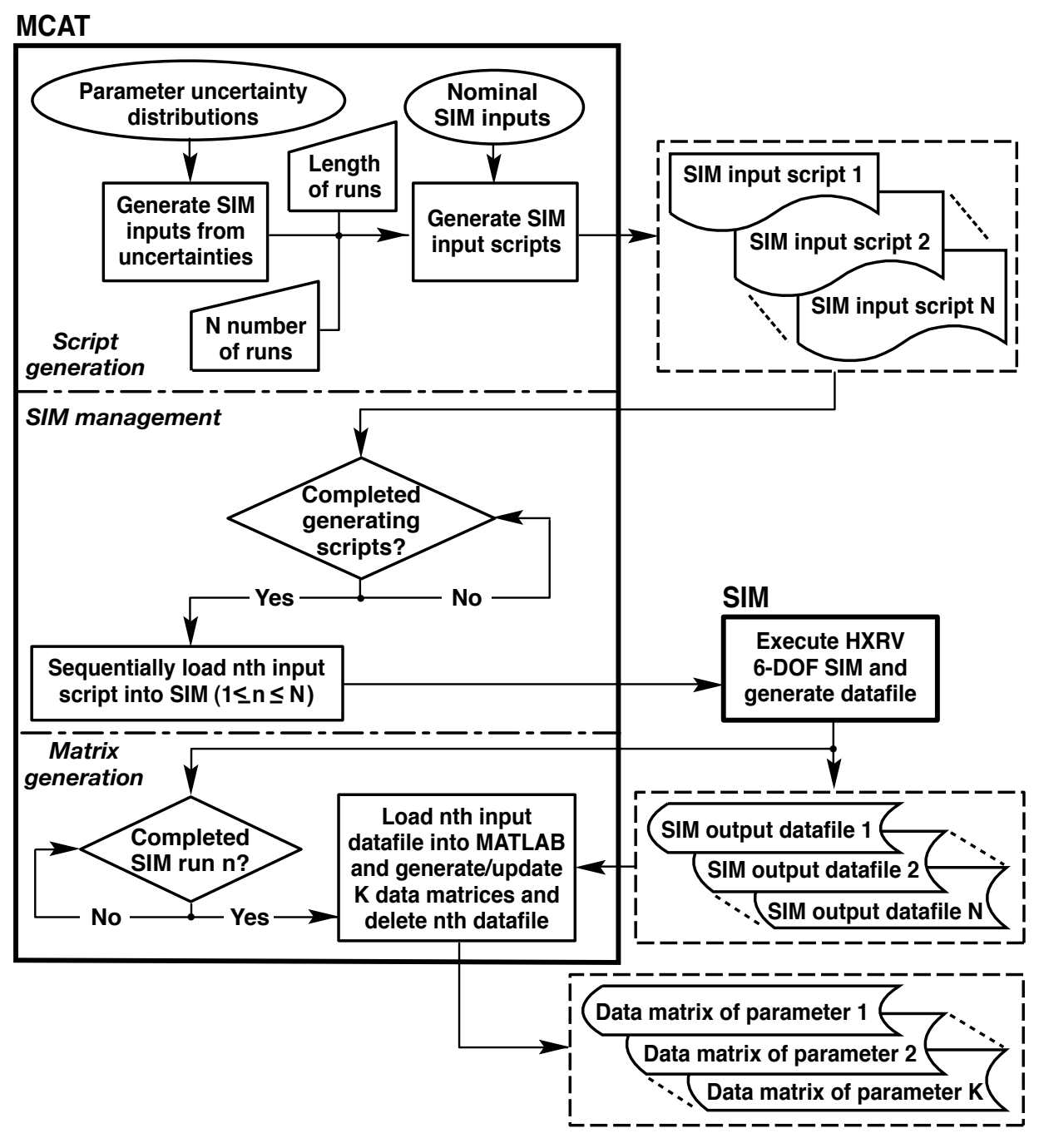

070266

Figure 3. Monte Carlo analysis tool overview.

For the MCAT, every input parameter that is varied has an uncertainty expressed in terms of a probability density function. The probability density functions for each input parameter are expressed in terms of its distribution type (uniform or Gaussian), a mean, and a standard deviation. The vast majority of the simulation input parameters are varied independently. Several parameters, such as the moments of inertia, were checked for consistency. If a parameter was found to be inconsistent with the other parameters with which it is correlated, the value was thrown out and recast until a consistent value was found. The input parameter values are based upon their particular probability density functions. They are selected within the \pm 3 sigma bounds for each run with either a uniform or Gaussian distribution (the distributions are specified by the user in the MCAT). If a distribution is Gaussian, the 3 sigma bounds encompass 99.87 percent of the possible values of the uncertain parameter. The uncertainties associated with a parameter were provided by each discipline responsible for that portion of the model (i.e. aerodynamics, propulsion, flight control, etc.) (ref. 7). 
As a part of each Monte Carlo analysis, summary statistics were extracted from the dataset and placed in a Monte Carlo report. A temporary $100 \mathrm{~Hz}$ dataset was created to extract the statistical information from the highest simulation data rate available. The temporary dataset was deleted after the statistics had been gathered. A number of statistics, including the maximum and minimum values, were recorded for certain parameters during particular flight phases. In addition, the run number associated with each maxima or minima was recorded. Table 2 shows a sample page from the Monte Carlo report. This report was examined and compared to previous reports to determine if any unusual cases or events had been generated in the latest set of Monte Carlo runs. Effective use of these summary statistics helped to reduce the long-term data storage requirements and identify runs of interest. The simulation scripts for each Monte Carlo analysis could be easily regenerated. This allowed for a simulation run to be repeated and more data acquired if, at a later date, a review of the summary or lower rate data indicated an item of interest.

In preparation for the second Mach 7 flight attempt, 1600 Monte Carlo simulation runs were conducted with the latest models and software as part of the final analysis. Many thousands of Monte Carlo simulation runs had been conducted prior to the generation of the final dataset as the analysis had been run continuously as the simulation models had been refined and the vehicle software matured. The number of simulation runs used for the final analysis was determined by examining the statistics of notable parameters, such as the maximum value for filtered normal acceleration, seen in figure 4. The asymptotic trend of the parameters showed that there would be little expected change in the output of the Monte Carlo analysis when performing more than 1600 runs.
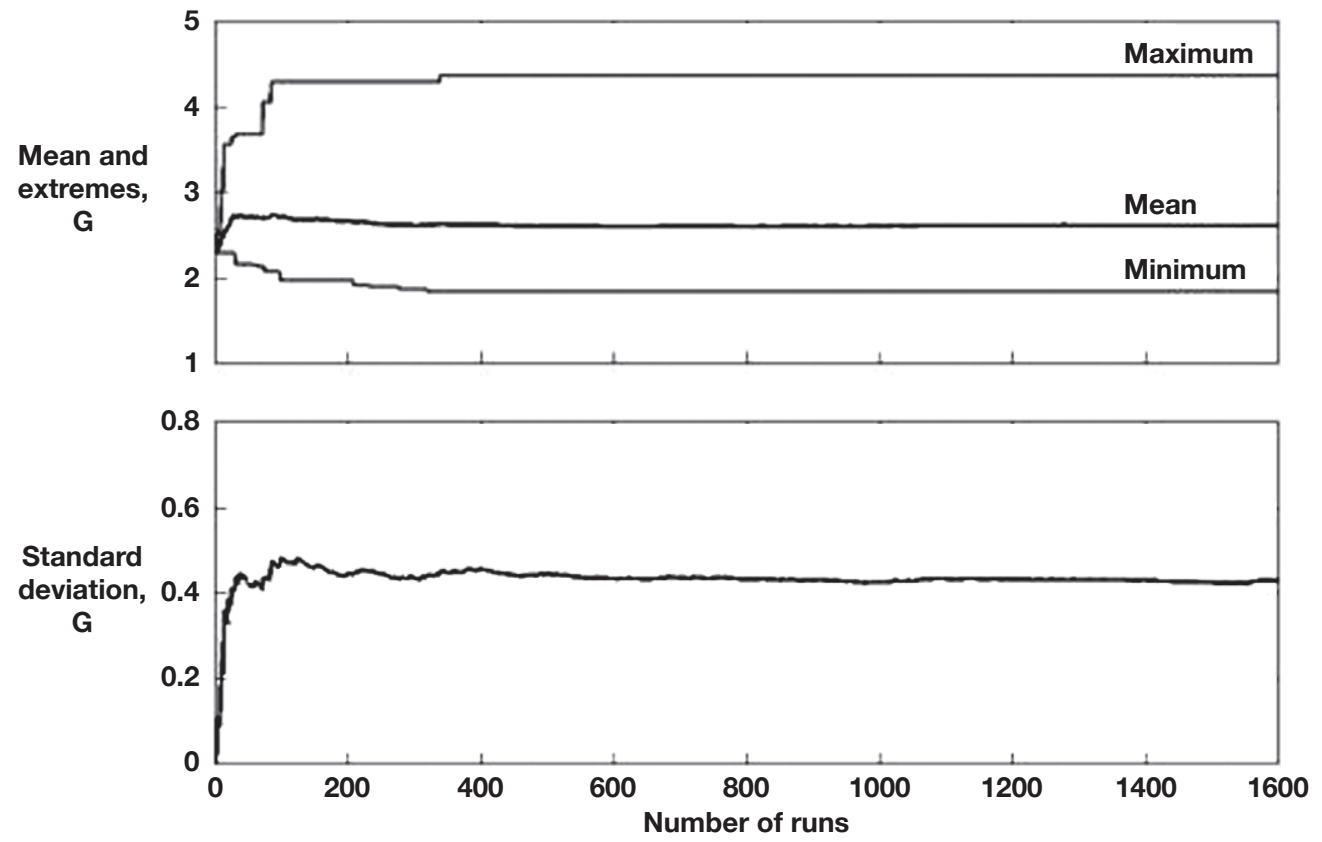

070267

Figure 4. Statistics for maximum filtered normal acceleration. 


\section{SIMULATION DESCRIPTION}

The Hyper-X program developed a high-fidelity 6-DOF nonlinear simulation model of the HXRV. The HXRV simulation does not model the HXLV and was usually initialized to the separation conditions from the HXLV. A separate 6-DOF simulation was developed to model the HXLV, and is beyond the scope of this report. A simplified model of the separation dynamics is included in the HXRV simulation. A separate, more detailed simulation, known as SepSim, was developed to fully model the HXRV separation from the HXLV and is beyond the scope of this report. The HXRV simulation was based on the standard DFRC simulation architecture (ref. 8) and contained detailed models that included the vehicle aerodynamics, mass properties, atmospheric, and wind models. Vehicle subsystems modeled in the simulation included the flight control system, actuator, engine and fuel systems, the inertial navigation system (INS), and the flush airdata sensing (FADS) system. The flight management unit (FMU) software models consisted of guidance, navigation, and flight control systems, in addition to the propulsion system control. Since most of the components in the research vehicle were single-string (not fault redundant), no failure modes were modeled in the simulation. The majority of the simulation core source code and models are written in Fortran 77 with several of the models consisting of autocode generated from Simulink ${ }^{\circledR}$ (The MathWorks, Natick, Massachusetts) models. The simulation graphical user interface is written in $\mathrm{C}$ programming language.

The simulation can be run in either a real-time mode or a non-real-time batch mode. The batch mode operation is faster than real-time and was used for most engineering analysis including Monte Carlo analysis. The real-time mode was used only when the simulation was connected to ground test hardware. The base simulation frame rate is $200 \mathrm{~Hz}$. Vehicle models and simulation routines are called at the appropriate multiples or submultiples of the base frame rate. Numerical integration of the simulation state information is performed using a second-order fixed-step Runge-Kutta algorithm optimized for fast execution. Oblate-Earth, 6-DOF equations of motion are employed. The simulation employs a command line interface along with a scripting capability. The scripting capability allowed for the simulation execution of script files containing multiple commands that had been strung together. The MCAT made extensive use of the simulation scripting capability to generate a unique simulation setup script for each Monte Carlo simulation run. Nearly every variable in the simulation is capable of being recorded in an external data file. The selection of output signals was done through the script files.

\section{MODEL UNCERTAINTIES}

The Monte Carlo analysis consisted of applying uncertainties to the simulation vehicle models. A total of 286 model uncertainties were used as a part of the final analysis for the second and third flights of the HXRV. The uncertainty distributions for each model were estimated using measurement error buildup, test data spread, or engineering judgment. The model uncertainties were generally developed by the engineering discipline team responsible for producing the model. These model uncertainties could be grouped in the following categories: separation condition, mass properties, control surface actuator performance, HXRV aerodynamics, separation aerodynamics, separation piston performance, FADS, atmosphere, winds, HXRV sensors, engine 
performance, and propulsion system performance. Uniform uncertainty distributions, described by their minimum and maximum values, were generally used as they produced the most conservative results. Uniform distributions were used for separation conditions, engine performance, winds, and inertial navigation system (INS) errors. To describe each Gaussian distribution, four numbers were used: mean, standard deviation (1-sigma), minimum, and maximum. The minimum and maximum numbers were used to limit the dispersions to better match their intended distributions and to maintain a 3-sigma limit on the applied uncertainties. The Matlab ${ }^{\circledR}$ rand or randn function was used to generate a random number with either a uniform or Gaussian distribution for each uncertainty. These random numbers were then linearly mapped to the model uncertainty distribution to generate a model uncertainty parameter for input to the simulation.

An overview of the Monte Carlo uncertainties is presented in Table 3. A detailed discussion of each area follows, with details presented where the data is not proprietary, sensitive, or otherwise restricted in distribution.

The HXRV simulation was initialized at the point of separation from the HXLV for the Monte Carlo analysis. The flight conditions used to initialize the HXRV simulation were derived from the project requirements document and the HXLV Monte Carlo simulation results. The HXLV Monte Carlo results generally fell within specified bounds. When a specific project requirement existed, that bound was used to determine the mean and \pm 3 sigma bounds for a particular condition since the requirement was more conservative than the HXLV Monte Carlo results. When no preexisting project requirement existed, the output of the HXLV Monte Carlo simulation was used. Table 4 details the separation conditions and uncertainties used to initialize the HXRV simulation for the Monte Carlo analysis.

The mass properties uncertainty model was developed by the HXRV structures team and is largely based on the accuracy of the test data. The vehicle weight, center of gravity, and principle moments of inertia were measured on the ground and adjusted for the final flight configuration. Measurement uncertainties and engineering judgment were used to determine the appropriate uncertainties. The mass property uncertainty values are presented in table 4 .

The HXRV control surface actuator models are discussed in detail in reference 9. A highfidelity, proprietary model of the HXRV control surface actuators was provided by the manufacturer, Moog (New York) and updated by the HXRV guidance, navigation, and control (GNC) team, which also developed an uncertainty model for the actuator model. This high-fidelity model was used for the HXRV Monte Carlo analysis for Flights 2 and 3. The HXRV GNC team also developed a simplified second-order model that approximated the actuator performance. This simplified model was used for Monte Carlo analysis prior to the first flight attempt and these model uncertainties are presented in table 4 . In general, the simplified actuator uncertainty model is more conservative than the high-fidelity model.

The HXRV vehicle aerodynamics model was developed from wind tunnel testing and computational fluid dynamics (CFD) (ref. 10). The aerodynamic uncertainty model was developed based on the wind tunnel testing and CFD results (ref. 11). In addition, work done in developing the X-33 uncertainty model (ref. 12) was leveraged in the uncertainty development. The aerodynamic 
coefficient uncertainty is a function of Mach number and engine operation. The aerodynamic uncertainties for cowl-closed flight decrease as the Mach number decreases. The aerodynamic uncertainties are increased for cowl-open flight and increased further while the scramjet is operating. The uncertainties in the principle aerodynamic coefficients during cowl-closed flight are presented as percents in table 4. Aerodynamic coefficient biases were used, but are not presented as they were not formulated in terms of a percent. The magnitude of the aerodynamic coefficient biases is generally small relative to the coefficients.

A simplified separation aerodynamics model was developed which applied delta force and moment increments to the free-flight HXRV aerodynamic coefficients to approximate the aerodynamic interactions expected to occur during the separation event. This model is known as the Sep Delta model. Uncertainties on these delta increments were developed and incorporated into the Monte Carlo analysis. The Sep Delta model was derived from SepSim analysis. A detailed presentation of the Sep Delta model along with its uncertainties is beyond the scope of this report. The principle purpose of the Sep Delta model in the HXRV Monte Carlo simulation was to replicate the spread in flight conditions the vehicle could be expected to encounter after the separation event. A detailed discussion of the SepSim analysis and results is contained in reference 13.

Two pistons were used to push the HXRV away from the HXLV during the separation event. A piston force model was developed, along with uncertainties, primarily from test data. A piston performance model was implemented in the HXRV simulation, in addition to SepSim. A detailed discussion of the piston performance model and uncertainties is beyond the scope of this report.

A flush airdata sensing (FADS) system was employed on the HXRV (ref. 14). The FADS system provided an angle of attack estimate that was blended with the inertial measurement following the engine test during the Mach 7 flight. The FADS system was only used real-time during the unpowered descent portion of the Mach 7 flight. The FADS performance uncertainties were examined by introducing uncertainties in the simulated pressure port measurements. There are three components to the FADS pressure port uncertainties. White noise was added to each frame as a uniformly-distributed number continuously varying from -1 to 1 . There was also an uncertainty in the pressure coefficient at each port, which was a function of Mach and alpha. Finally, a PPT (pressure port transducer) measurement uncertainty was added as a normallydistributed number between -1 and 1 . For the Monte Carlo analysis, uncertainties were applied only to the pressure ports used as part of the angle of attack estimation algorithm. Table 4 details the FADS uncertainties.

The HXRV simulation contains a separate atmosphere model for each month. This model was developed by the DFRC meteorological group and tailored for the expected HXRV engine test location. The model is derived from Global Reference Atmospheric Model (GRAM-95) data (ref. 15). The atmosphere model used by the HXRV onboard software is constant during a Monte Carlo run and is set to the expected flight month. Atmospheric uncertainties are modeled by choosing a uniform random month for the atmosphere model in the nonlinear simulation. By randomly varying the simulation atmosphere model between the 12 available models, adequate uncertainty was applied to the HXRV onboard software relative to the simulated values. 
North-South, East-West, and vertical wind components are independently varied every $10,000 \mathrm{ft}$. North-South and East-West wind data was provided by the DFRC meteorology group. Vertical wind mean data is from GRAM-95, and also varies by altitude and month. Because of sparse statistical data for vertical winds over the ocean, a worst-case 3 sigma value of $10 \mathrm{ft} / \mathrm{s}$ was used. Table 4 provides sample wind uncertainties.

A high-fidelity sensor model, including uncertainties, was developed to model the performance of the INS contained in the H-764 Honeywell flight control computer (Honeywell, Inc., Minneapolis, Minnesota). The INS package is capable of utilizing global positioning system (GPS) updates to aid the position and attitude solution, but the HXRV used the pure inertial solution throughout its mission, so GPS performance was not included in the sensor model. Information used to develop the high-fidelity sensor model is proprietary and therefore, the model details are not presented here.

The HXRV simulation contains an engine database that approximates the steady-state scramjet engine thrust and moments, hereafter referred to as performance (ref. 16). The simulation engine database consists of maximum and minimum values as a function of flight condition and fuel-to-air ratio. Engine performance is varied for each run by setting an engine performance parameter that selects a point between the minimum and maximum values in the database. Uniformly distributed values between 0 and 1 were used to vary the engine performance. The engine performance parameter was set at the beginning of a Monte Carlo simulation run and not varied thereafter. A value of 0.5 corresponds to the midpoint of the maximum and minimum values and is considered the nominal engine performance.

Uncertainties in the HXRV scramjet fuel system performance were modeled in the Monte Carlo analysis. Uncertainty in the fuel flow, igniter flow, and airflow were also modeled.

Most of the applied uncertainties were independent of each other; however, some reasonableness checks were performed on correlated parameters. These included angle of attack, pitch attitude, and flight path angle, as well as altitude, velocity, and dynamic pressure. Moments of inertia were also evaluated to ensure that the sum of two principle axes would be greater than the third axis.

In addition, the HXRV simulation random number seed was set by the Monte Carlo tool. The random number seed is used to initialize the random functions in the HXRV simulation that apply noise to the sensors and FADS pressure measurements. This explicit setting of the random number seed allowed for repeatability of a single Monte Carlo run.

\section{MISSION AND TRAJECTORY SENSITIVITY ANALYSIS}

Key relationships between uncertainties and performance were determined using a sensitivity study. In general, the project was most interested in determining the uncertainty combinations that would produce the maximum or minimum of a particular metric. For example, one metric was the vehicle positive acceleration caused by the scramjet engine operation. As a result, the maximum 
and minimum positive acceleration values were of interest along with any key uncertainties influencing the value.

Performance metrics were unique to the various mission segments. The following were some of the metrics that were tracked during the separation event and parameter identification maneuvers: surface command rates and positions, vehicle attitude rates and angles, and normal acceleration. The most important performance metrics were the engine-on flight conditions: primarily angle of attack, Mach number, and dynamic pressure. These metrics were used to provide the scramjet team with the expected flight conditions for their own detailed off-nominal analysis of the scramjet performance. The robustness of the guidance algorithm to off-nominal engagements was assessed by examining the impact of off-nominal headings when the algorithm was engaged. Over the rest of the descent to the ocean, surface commands and positions, altitude error, vehicle attitude, and flight condition were tracked. The vehicle orientation, velocity, splashdown point, aim point error, and time aloft were then determined at the end of each run. This final information was used to evaluate the performance of the guidance routine and to develop a splash point boundary for range clearance.

Maximums and minimums of these parameters of interest were drawn on scatter plots versus each model uncertainty input for a set of Monte Carlo runs to determine the uncertainty parameters to which the vehicle performance was most sensitive. An obvious example is seen in figure 5, which shows how increasing the drag (axial force aerodynamic coefficient) decreases the distance traveled.

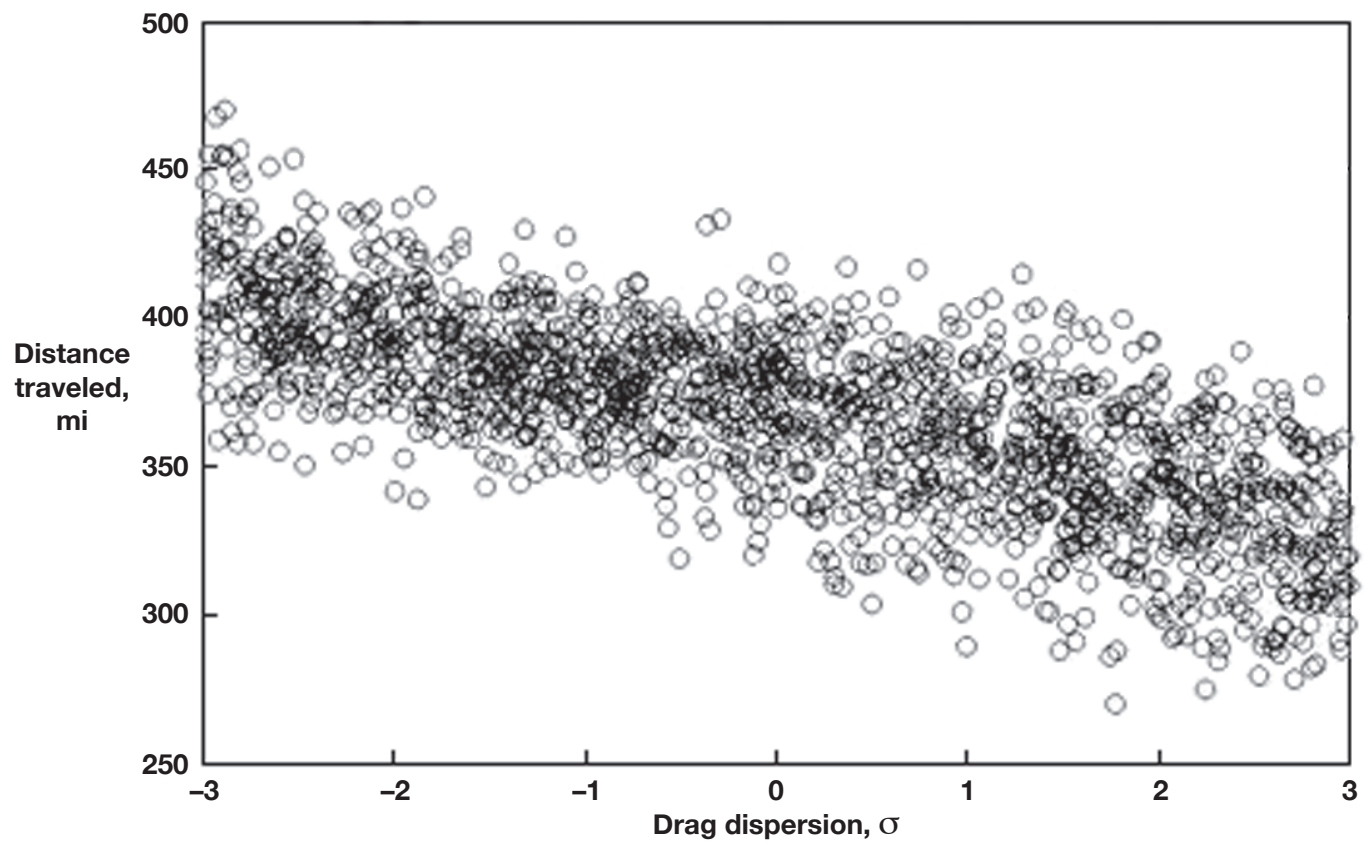

070268

Figure 5. Hyper-X Research Vehicle down range versus drag dispersion. 
The HXRV was found to be sensitive to a model uncertainty if it caused the vehicle to reach a maximum or minimum limit of some parameter of interest, such as angle of attack, normal acceleration, or control surface deflection. In addition, if the vehicle exhibited an undesirable behavior, such as a pitch or roll oscillation, the cause(s) were noted as parameters of interest. Before the first flight attempt, a ranked list was formed of the model uncertainties to which the HXRV performance metrics and trajectory were most sensitive.

1. Separation angle-of-attack

2. Separation sideslip angle

3. Separation pitch attitude

4. Separation heading

5. Separation altitude

6. Separation Mach

7. Lateral center of gravity location

8. Actuator damping ratio

9. Axial force aerodynamic coefficient (approximately equivalent to Drag)

10. Normal force aerodynamic coefficient (approximately equivalent to Lift)

11. Pitching moment aerodynamic coefficient

12. Error in pitch attitude caused by mounting and measurement

Stress testing was conducted with combinations of these parameters being set at or beyond their minimum or maximum expected values. This testing resulted in a handful of cases that stressed the vehicle performance at varying points throughout the mission. These limited numbers of cases could be run quicker than a full Monte Carlo analysis to assess vehicle performance, while still stressing the vehicle software and performance. These stress tests were used to quickly examine design changes to the flight control laws and guidance algorithm. In addition, the stress test analysis partially accounted for the unknown unknowns present in every flight research program by examining the vehicle performance with what are believed to be unrealistic model uncertainties. These tests provided an assessment of the vehicle robustness in excess of that which is expected to be required.

\section{VALIDATION TESTING}

Two types of flight hardware and software validation tests were performed: hardware-inthe-loop (HIL) and aircraft-in-the-loop (AIL) tests (ref. 17). The purpose of HIL testing was to validate the hardware and software performance of the flight control computer, which is a portion of the flight management unit (FMU). For HIL testing, the FMU was connected to the simulation. Simulated inertial sensor data was provided to the FMU by the simulation. The flight software running on the FMU generated control surface commands and propulsion control valve commands 
that were in turn fed to the simulation. The number of test cases run in the HIL environment was limited because of the test complexity and time involved. The AIL tests were similar to the HIL tests but also included the vehicle flight actuator controller and actuators as part of the test configuration. The AIL testing placed flight hardware at risk, so an even more limited number of test cases were chosen for this type of testing.

Taking these factors into consideration, a small set of runs was chosen for validation testing from the thousands of Monte Carlo runs. Approximately 20 runs were performed using the HIL setup, and less than 5 runs were conducted as a part of AIL testing. The runs chosen for HIL and AIL testing were chosen from a Monte Carlo dataset by finding the minimum number of runs that bounded some desired aspect of the mission. For example, figure 6 shows the 5 cases found which bounded 90 percent of the altitude profiles from 1600 Monte Carlo cases. In general, the HIL cases were chosen to bound the flight conditions seen in the Monte Carlo analysis and the AIL cases were chosen to stress some aspect of the control surface actuators such as response to a large step change, maximum/minimum deflection, or high levels of surface motion. An automated tool was developed which selected the minimum number of cases that met the desired criteria. Table 5 shows the criteria the tool maximized or minimized during a given mission segment. The tool worked its way through the Monte Carlo dataset and selected a run for HIL testing if it was 90 percent of the way to a specified bound. Cases exceeding the 90 percent threshold for multiple specifications were ranked higher and the highest ranked cases were chosen for HIL analysis.

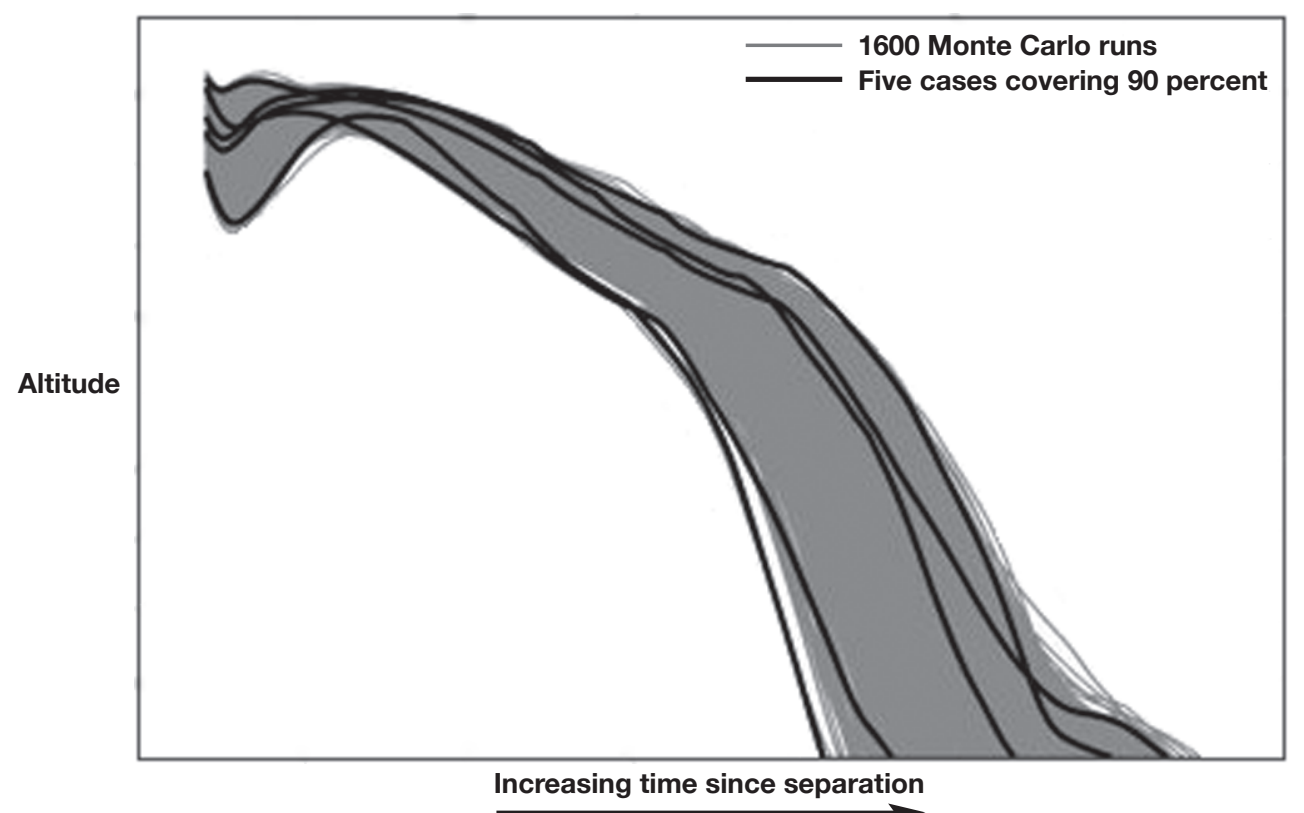

070269

Figure 6. Validation test cases compared to full Monte Carlo results. 


\section{FLIGHT DATA COMPARISONS TO PREFLIGHT MONTE CARLO RESULTS}

A summary of the HXRV in-flight performance comparison with preflight Monte Carlo results is discussed for the Mach 7 and Mach 10 flights, with an emphasis placed on highlighting modeling shortfalls. Reference 18 provides a detailed discussion of the HXRV performance and comparisons with Monte Carlo data during the Mach 7 flight and reference 19 provides the same for the Mach 10 flight.

Flight results are presented for the time period after the separation event. The HXRV simulation only roughly approximates the separation event and this time period is fully modeled in detail by the HXRV separation simulation.

\section{The Mach 7 Mission}

For the Mach 7 flight, the in-flight performance, when compared to Monte Carlo predictions, indicates that the analysis was fairly accurate at predicting actual flight performance and bounds. Notable differences between the Monte Carlo predictions and the in-flight performance are discussed. Figure 7 displays the inertial angle of attack during the scramjet test. In figures 7-15, flight data is compared to a nominal simulation run started at the in-flight separation point. Monte Carlo data is represented on figure 7 by the gray bands that show the bounds for 66 percent of the runs, 95 percent of the runs, and the minimum and maximum values.

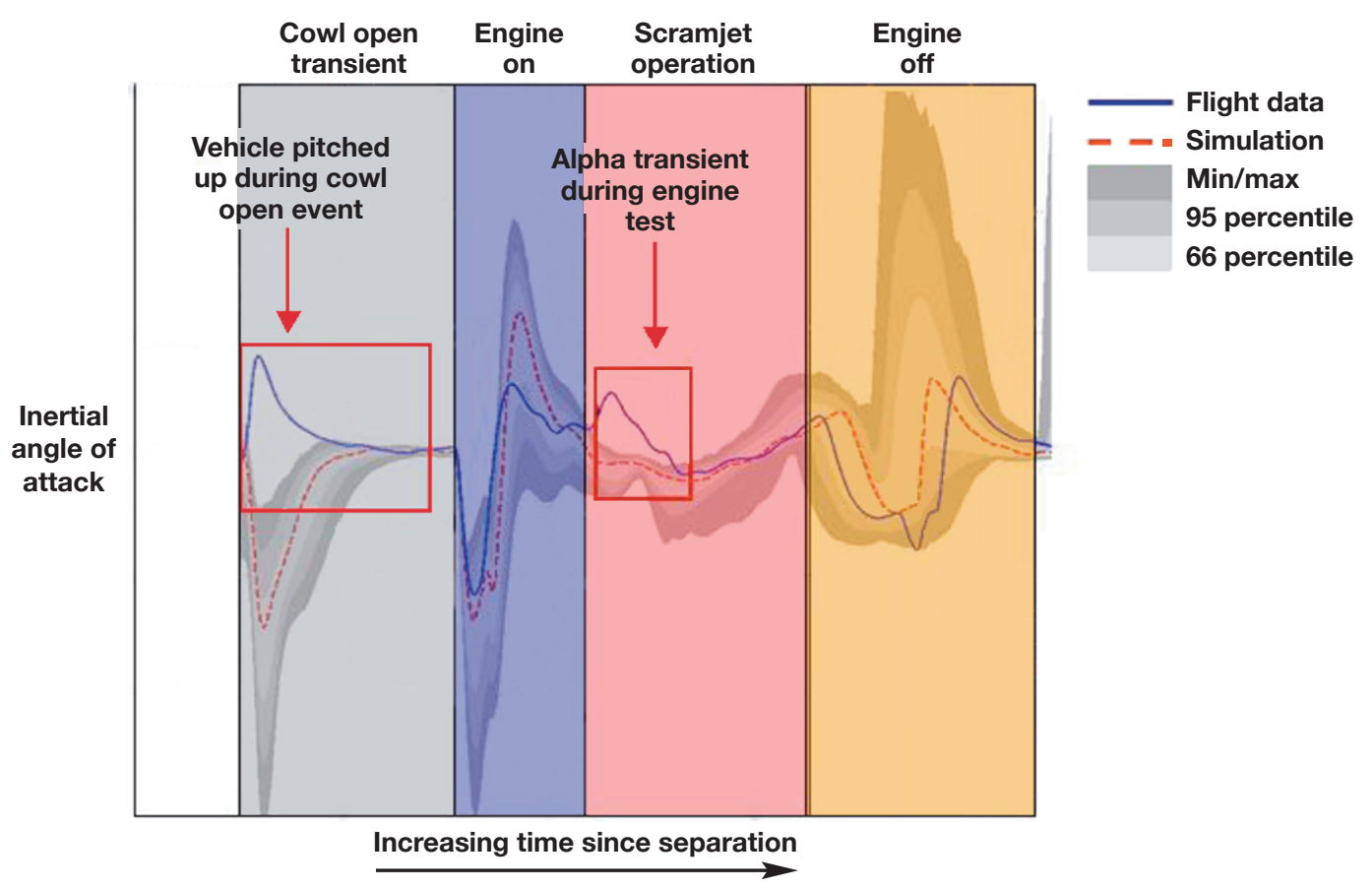

070270

Figure 7. In-flight inertial angle of attack during scramjet test conditions compared to Monte Carlo predictions for the Mach 7 mission. 
The cowl-open transient prior to the engine test resulted in the vehicle nose pitching up, whereas the nominal and Monte Carlo preflight analysis predicted a nose-down transient as shown in figure 7. The inaccurate prediction of the direction of the cowl-open transient was likely caused by an incorrect understanding of the unsteady aerodynamics caused by the cowl door opening.

The inertial angle-of-attack response during the engine test is compared with the preflight Monte Carlo results in figure 7. During the engine test, the HXRV maintained the engine test conditions well within the requirements of $\pm 0.5^{\circ}$ angle of attack. The inertial angle of attack fell outside the Monte Carlo bounds for a few seconds during the engine test as the igniter was removed from the fueling profile. This event is an example of the difficulties in modeling the complexities of the scramjet operation, as it was not covered by the Monte Carlo preflight predictions. The HXRV simulation contains a simplified engine model that is essentially a table lookup based on flight condition and therefore, does not fully model the dynamics of scramjet operation.

Following the scramjet experiment, the HXRV increased the angle of attack to arrest the buildup in dynamic pressure and heating. During the recovery maneuver, the HXRV experienced small amplitude angle of attack oscillations at a frequency of approximately $0.65 \mathrm{~Hz}$ as shown in figure 8. The preflight Monte Carlo predictions did not include any cases with sustained oscillations during the recovery maneuver. The cause of the oscillations is not fully understood. After the recovery maneuver, the vehicle transitioned to the descent mode.

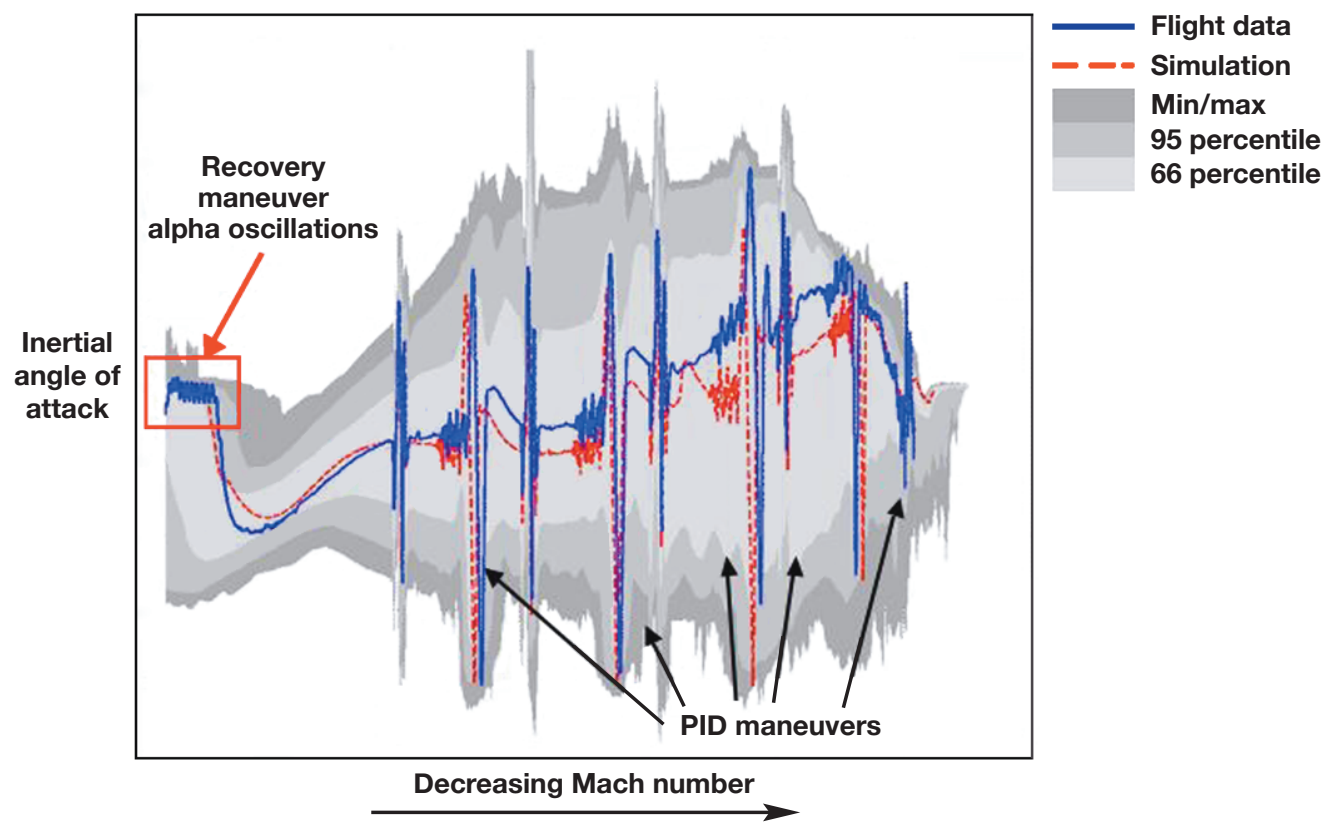

070271

Figure 8. Inertial angle of attack compared to Monte Carlo predictions for the Mach 7 mission. 
The vehicle maintained controlled flight and performed well during the descent. Figure 8 also shows that the inertial angle of attack was within the preflight predictions during the descent portion of the mission. The large changes in angle of attack during the descent are caused by preprogrammed PID maneuvers, which were preformed at integer Mach numbers.

Figure 9 shows that the flight altitude profile was close to the nominal simulation results and was well within the Monte Carlo predictions. The bank angle was within Monte Carlo predictions throughout the descent except for a deviation late in the descent, seen in figure 10. At that point, the HXRV banked approximately $30^{\circ}$ left wing down. The cause of this upset has not been conclusively determined, but the upset might have been caused by winds or unmodeled transonic aerodynamics. The impact location was well within the preflight prediction as shown in figure 11. Figure 12 shows the HXRV ground track following separation from the HXLV overlaid on the preflight Monte Carlo predictions. The California coastline is included in figure 12 for approximate scale and orientation.

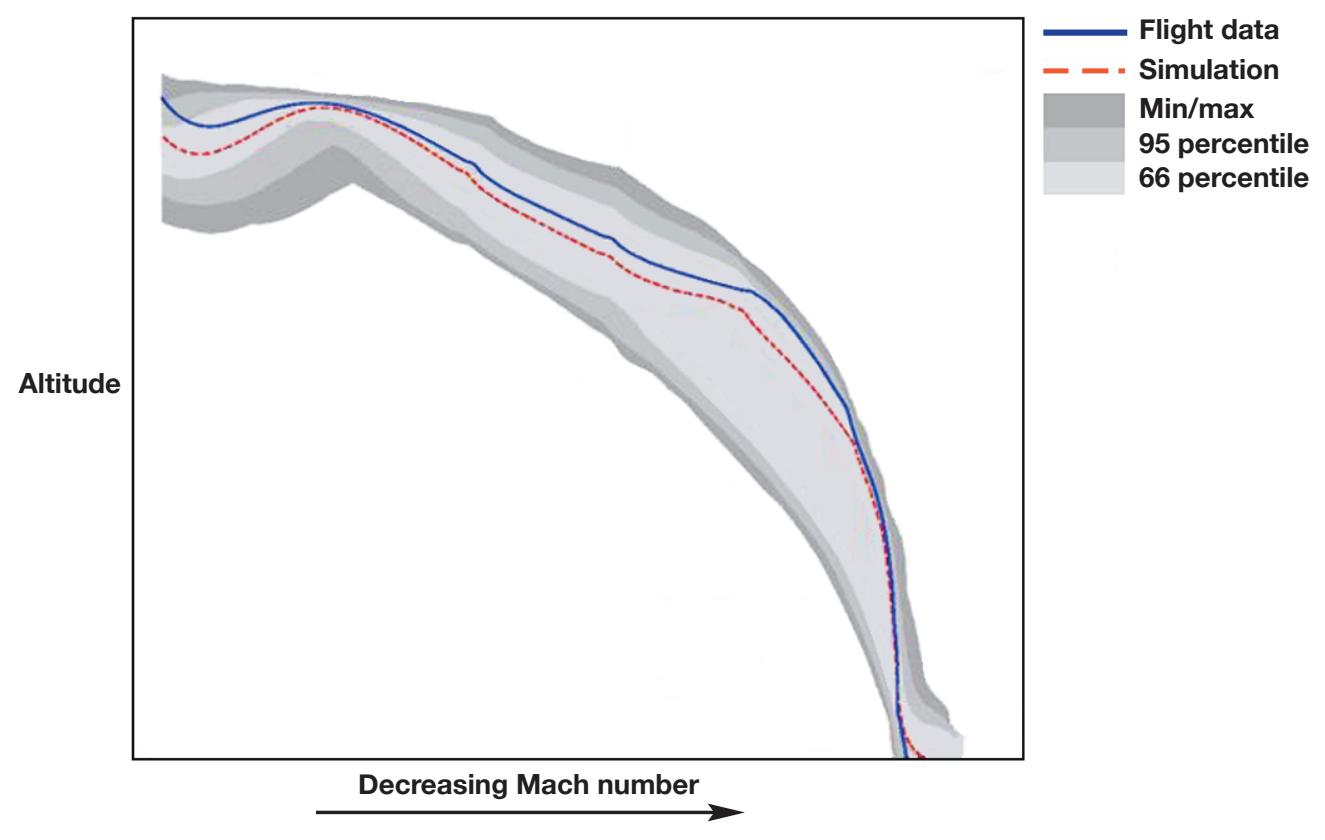

070272

Figure 9. Inertial altitude compared to Monte Carlo predictions for the Mach 7 mission. 

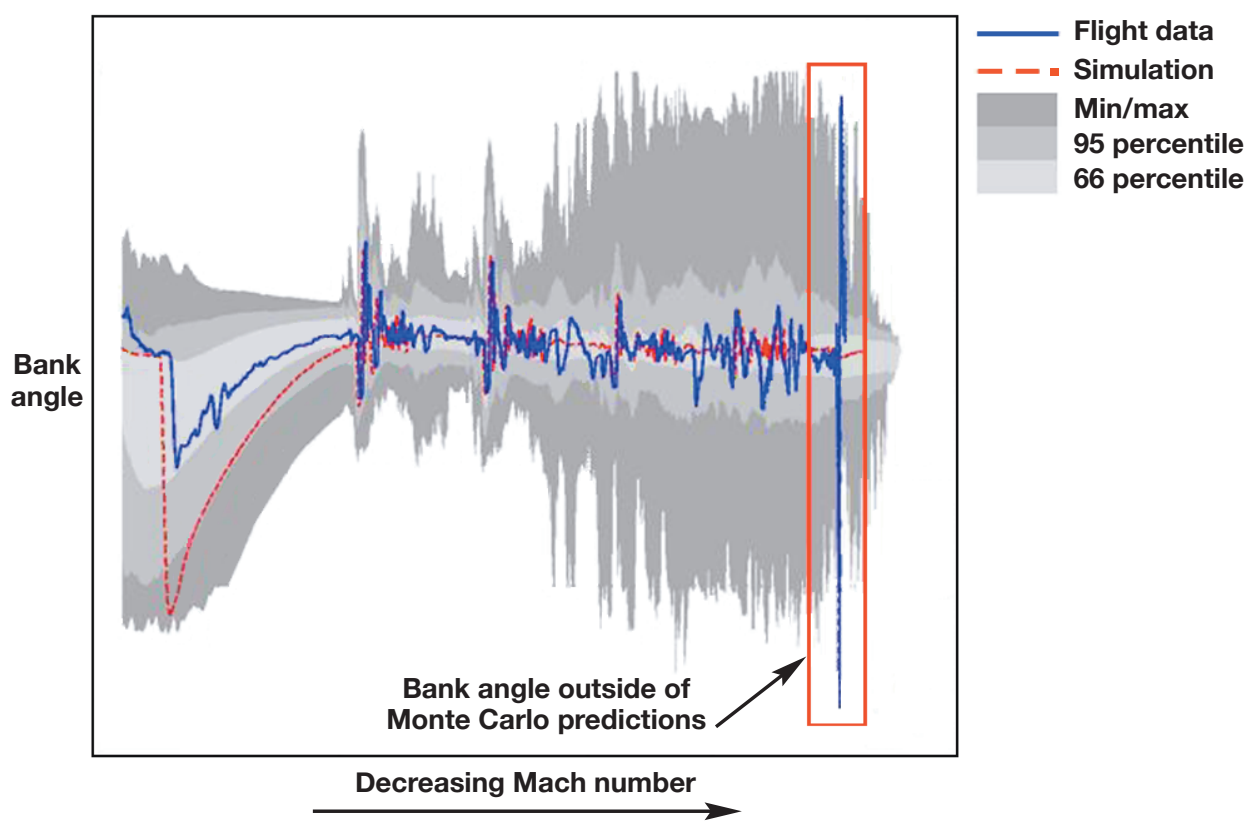

070273

Figure 10. Bank angle compared to Monte Carlo predictions for the Mach 7 mission.

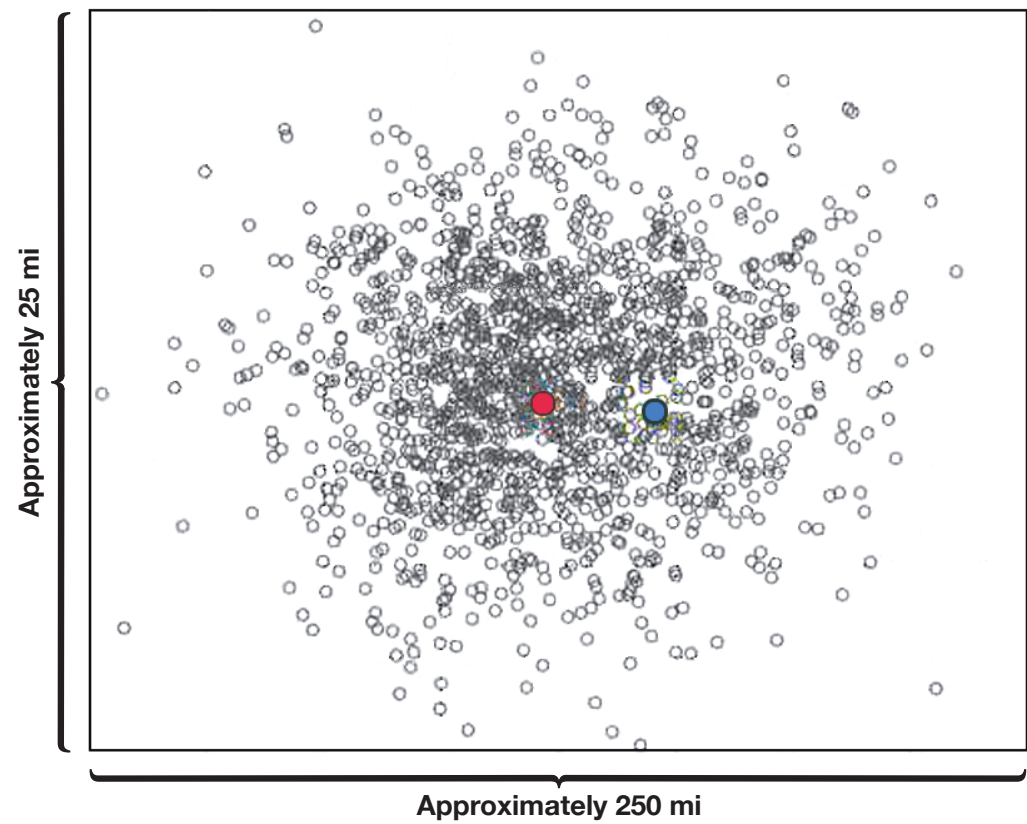

Splash point

Aim point

MC splash point

070274

Figure 11. Mach 7 mission splashpoint compared to preflight Monte Carlo predictions. 


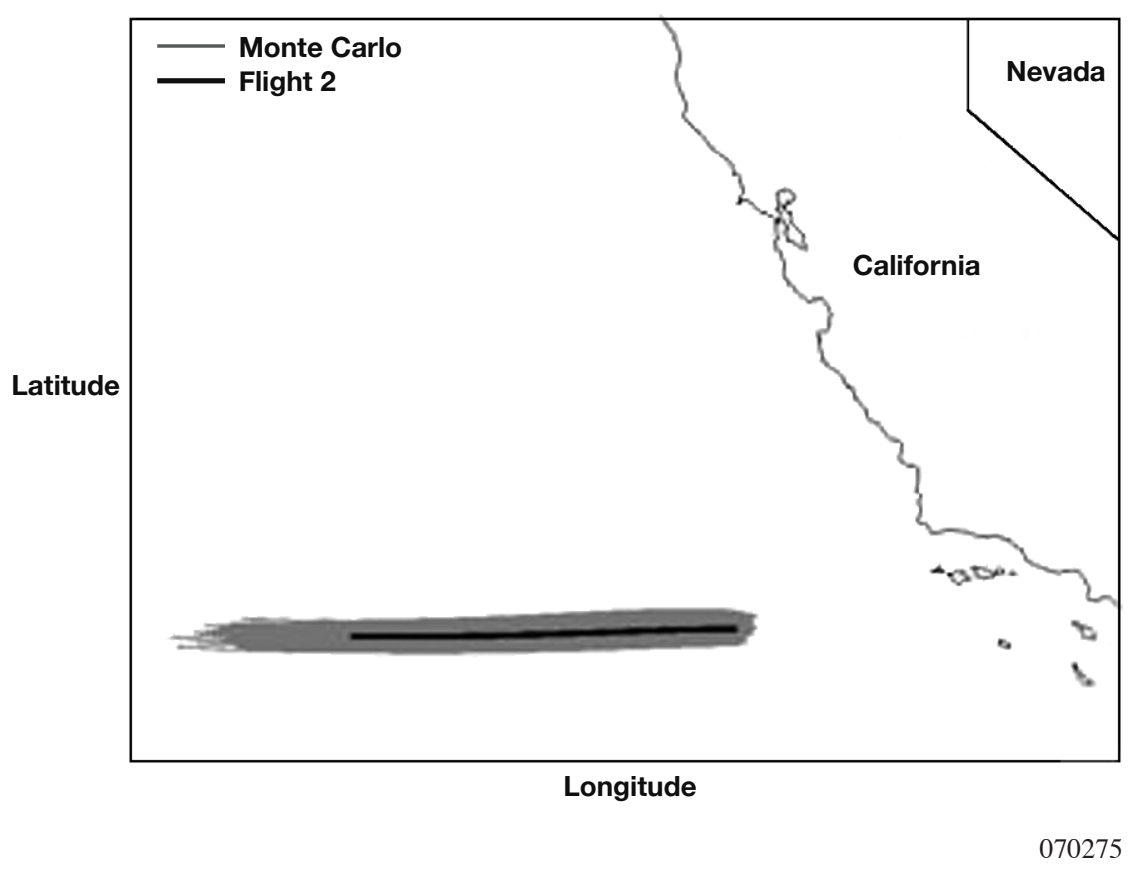

Figure 12. Mach 7 mission ground track compared to preflight Monte Carlo predictions.

\section{The Mach 10 Mission}

The HXRV generally flew within the Monte Carlo bounds for the Mach 10 flight, with several notable exceptions (ref. 19). Figure 13 shows the in-flight angle-of-attack performance during the engine test. A slight pitch up, instead of a pitch down (as predicted by the nominal simulation), occurred when the cowl door opened. This pitch up occurred in both the Mach 7 and Mach 10 missions. Before the Mach 10 flight, the engine database uncertainties were increased to account for the discrepancy seen in the Mach 7 flight. As a result, the in-flight angle-of-attack performance when the cowl door opened fell within the Monte Carlo predictions for the Mach 10 flight.

The expected longitudinal upsets, when the engine was turned on and off, were within the Monte Carlo predictions. During the remainder of the engine test, the HXRV maintained the required angle of attack. As seen in the Mach 7 flight, the inertial angle of attack fell outside of the Monte Carlo bounds during the engine test as the igniter was removed from the fueling profile. Figure 14 shows that during the engine test, the AMW deflections were near the Monte Carlo bounds, which is believed to result from an inaccurate prediction of the nominal $\mathrm{Cmo}$ (pitching moment at zero degree angle of attack) by the aerodynamic and engine databases. This discrepancy indicates that a larger Cmo uncertainty might have been appropriate. 


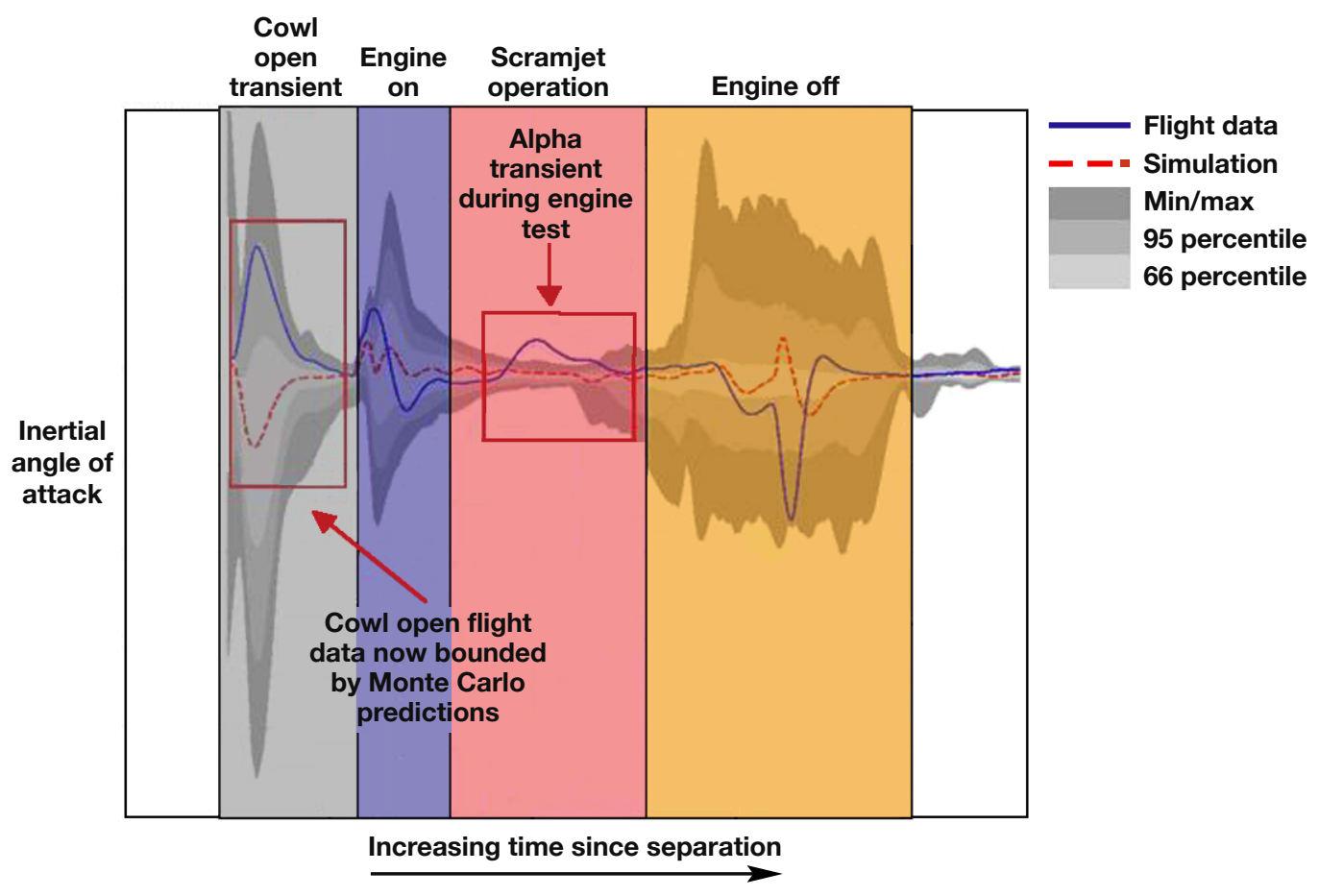

Figure 13. In-flight inertial angle of attack during scramjet test conditions compared to Monte Carlo predictions for the Mach 10 mission.

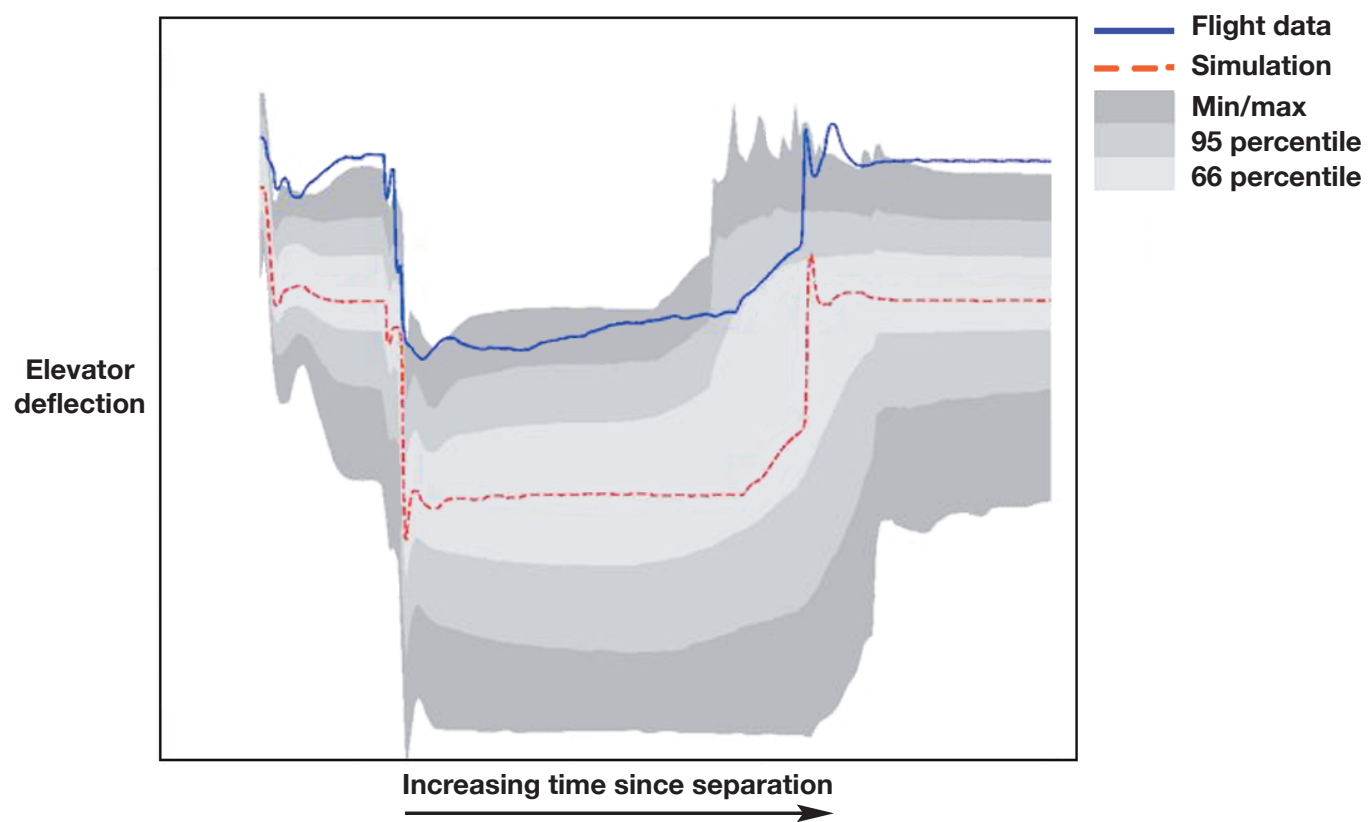

Figure 14. In-flight elevator position compared to Monte Carlo predictions for the Mach 10 mission. 
Following the engine test, the HXRV successfully closed the engine cowl door and pulled to the desired angle of attack as part of the recovery maneuver. After approximately $10 \mathrm{~s}$, the HXRV began to slowly rock approximately $\pm 10^{\circ}$ about the commanded bank angle, and the rocking grew to as much as $\pm 20^{\circ}$ about the command when guidance started maneuvering the vehicle in the direction of the aim point. During the same time period, the internal engine pressures indicated that air had started to flow through the engine, resulting in a pressure increase on the aft underbody of the vehicle, which pushed the nose down. The HXRV responded by commanding the elevators to move to a more negative deflection to bring the nose back up. Figure 15, which shows the left AMW deflection from flight compared to the Monte Carlo data, illustrates the primary effect of air flowing through the engine. The AMW deflection was outside of the Monte Carlo bounds at high Mach numbers. Another event of note during this time period was a step change in the elevator command of several degrees to counter a longitudinal disturbance. This disturbance is believed to have been caused by a venting in the fuel system and the spontaneous ignition of igniter in the engine during this process. The internal engine pressures dropped shortly before the Mach 8 PID maneuver, and the HXRV flew generally as predicted from Mach 8 and below. The AMW deflections continued to be outside of the Monte Carlo bounds until approximately Mach 5 when they started to track the nominal preflight predictions. Unexpected airflow through the engine and the unexpected spontaneous fuel ignition during the venting process are examples of phenomena that were not anticipated and thus not modeled as part of the Monte Carlo analysis. It is not known if the AMW deflections at the higher Mach numbers were outside the Monte Carlo bounds solely because of air flowing through the engine or if a mismatch in the predicted aerodynamics is also a cause. The HXRV flew as predicted during the rest of the descent after about Mach 5.

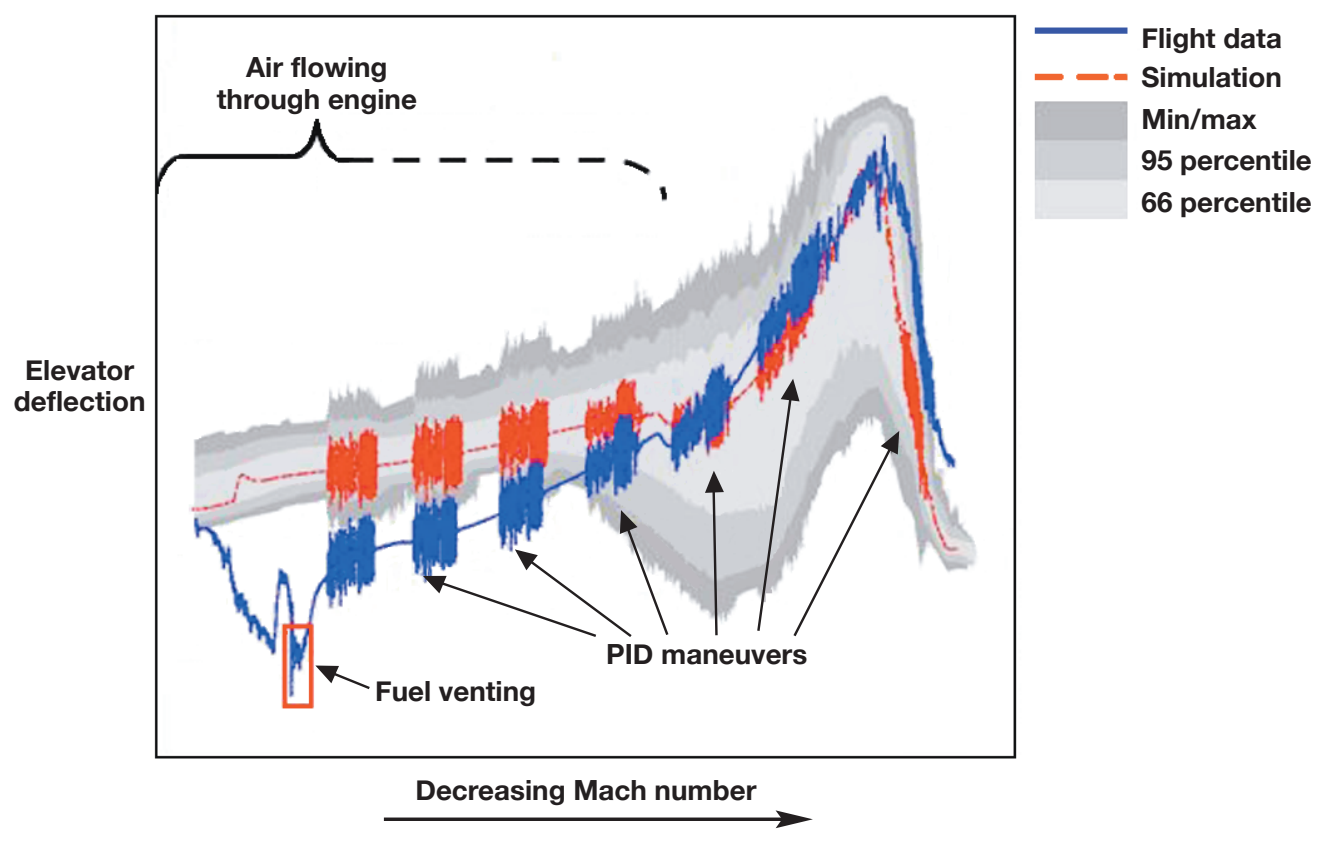

070278

Figure 15. Hyper-X Research Vehicle Mach 10 mission elevator position compared to Monte Carlo data. 


\section{OBSERVATIONS AND LESSONS LEARNED}

It is fairly obvious that a vehicle simulation is only as good as the models of which it is composed. It is also obvious that a Monte Carlo analysis is only as good as the uncertainties used. In the case of the HXRV, some sets of uncertainties were known better than others. For example, the mass properties of the vehicle were measured directly and therefore were very well known with the uncertainty being largely driven by measurement accuracy. On the other hand, the HXRV was the first airframe-integrated scramjet-powered vehicle operated in flight. As a result, there was greater uncertainty in the aerodynamics, cowl motion transients, and engine operation because of the limited flight experience with this class of vehicle and the limited amount and applicability of wind tunnel testing. These models carried correspondingly larger uncertainties and, based on flight results, possibly should have carried larger uncertainties.

The aerodynamic and engine performance uncertainties used in the HXRV simulation were primarily applied as a scalar to the vehicle forces and moments. The flight data indicated inaccurate predictions in the vehicle Cmo in several instances; therefore an improvement to the HXRV aerodynamic uncertainty model would have been the addition of larger biases to the total vehicle forces and moments.

Monte Carlo analysis is very useful for predicting vehicle performance in the presence of known uncertainties. If, however, the uncertainties are believed to be conservative, it can provide a false sense of security and the perception that the vehicle will be robust to anything that could happen. Monte Carlo analysis also cannot account for unknown unknowns. The HXRV Mach 7 and Mach 10 missions experienced several events that were not anticipated and hence not modeled in the simulation. The unexpected pitch-up when the cowl door opened and the oscillations that occurred during the recovery maneuver during the Mach 7 mission are excellent examples of unanticipated events not modeled by the simulation and therefore not a part of the Monte Carlo analysis. The HXRV GNC team attempted to account for these unknown unknowns by maintaining conservative uncertainty bounds, primarily using uniform uncertainty distributions to produce a larger number of cases at the "corners," and performing stress tests past the uncertainty bounds. Although the exact uncertainties and unknown unknowns were not captured within the Monte Carlo bounds, the system was robust enough to account for them without catastrophic consequences.

The Monte Carlo analysis tools turned out to be fairly complicated. Keeping track of the hundreds of model uncertainties and the interactions between the Matlab ${ }^{\circledR}$-based tools and the simulation turned out to be a straightforward, but involved process. The simulation models and uncertainties evolved greatly between the initial Monte Carlo capability developed for Flight 1 and that used for Flight 3. It is extremely important that any Monte Carlo analysis tool be straightforward to use and easily modifiable, especially when the tool is projected to be in use for many years.

The Monte Carlo analysis tools were not under configuration control until late in the project. This lack of configuration control was not a serious problem since modifications to the tool were typically done by only one or two people working closely together, however, the HXRV simulation was under configuration control from the beginning. It became desirable to place the tool under configuration control later in the program since it was used for an important preflight analysis. The 
majority of the uncertainty values were contained in the Matlab ${ }^{\circledR}$ scripts, which were a part of the Monte Carlo analysis tools, however, a number of the uncertainty values were contained in the HXRV simulation and a random number was input from the tools to set the uncertainty in the simulation. There would have been several advantages in placing the uncertainties in the HXRV simulation. First, all of the uncertainties would have been in the same tool and been under configuration control from the beginning. Second, the Matlab ${ }^{\circledR}$ scripts that generated each simulation run could have been much simpler if they had only to generate a set of random numbers for input to the simulation. An alternative approach would have been to incorporate all of the Monte Carlo run generation capabilities in the HXRV simulation. The main drawback to either of these approaches is that the simulation would have grown even more complex and potentially difficult to modify. The decision to place the Monte Carlo uncertainties and capabilities in the vehicle simulation is one that is specific to each project and depends on the complexity of both the simulation and the desired Monte Carlo analysis.

\section{CONCLUSION}

An overview of the Hyper-X research vehicle Monte Carlo analysis tools, model uncertainties, and analysis was presented. The methodology for selecting hardware validation test cases from the Monte Carlo data was described. The results of the preflight Monte Carlo analysis were compared with flight data, with an emphasis placed on highlighting modeling shortfalls. Modeling and Monte Carlo analysis lessons learned were presented. The preflight Monte Carlo analysis indicated that the $\mathrm{X}-43 \mathrm{~A}$ control system was robust to the preflight uncertainties and provided the Hyper-X project an important indication that the vehicle would likely be successful in accomplishing the mission objectives. The X-43A accomplished all of the objectives during the two successful flights, however, the actual in-flight performance was not entirely captured within the Monte Carlo bounds. The X-43A flight control laws and guidance algorithms were robust enough as a result of the preflight Monte Carlo analysis, to ensure that the vehicle was able to handle the unexpected without undue consequences. 


\section{REFERENCES}

1. Freeman, Delma C. Jr., David E. Reubush, Charles R. McClinton, Vincent L. Rausch, and J. Larry Crawford, The NASA Hyper-X Program, NASA TM-1997-207243, 1997.

2. X-43A Mishap Investigation Board, Report of Findings: X-43A Mishap, Vol. 1, 2003.

3. Marshall, Laurie A., Griffin P. Corpening, and Robert Sherrill, "A Chief Engineer's View of the NASA X-43A Scramjet Flight Test,” AIAA 2005-3332, May 2005.

4. Marshall, Laurie A., Catherine Bahm, Griffin P. Corpening, and Robert Sherrill, "Overview With Results and Lessons Learned of the X-43A Mach 10 Flight,” AIAA 2005-3336, May 2005.

5. Morelli, Eugene A., Stephen D. Derry, and Mark S. Smith, “Aerodynamic Parameter Estimation for the X-43A (Hyper-X) from Flight Data," AIAA 2005-5921, August 2005.

6. Baumann, Ethan, Tailored Excitation for Frequency Response Measurement Applied to the X-43A Flight Vehicle, NASA TM-2007-214609, 2007.

7. Jones, Thomas P., and Ethan Baumann, Evaluation of the X-43A Scramjet Engine Controller Performance by Monte Carlo Technique, NASA TM-2003-212036, 2003.

8. Norlin, Ken A., Flight Simulation Software at NASA Dryden Flight Research Center, NASA Technical Memorandum 104315, 1995.

9. Lin, Yohan, Ethan A. Baumann, David M. Bose, Roger Beck, and Gavin Jenney, Tests and Techniques for Characterizing and Modeling X-43A Electromechanical Actuators, NASA TM (To be published).

10. Walter C. Engelund, Scott D. Holland, Charles E. Cockrell Jr., and Robert D. Bittner, "Aerodynamic Database Development for the Hyper-X Airframe-Integrated Scramjet Propulsion Experiments," Journal of Spacecraft and Rockets, Vol. 38, No. 6, NovemberDecember 2001.

11. Davis, Mark C., and J. Terry White, "Flight-Test-Determined Aerodynamic Force and Moment Characteristics of the X-43A at Mach 7.0," AIAA 2006-8028, November 2006.

12. Brent R. Cobleigh, Development of the X-33 Aerodynamic Uncertainty Model, NASA/TP-1998-206544, 1998.

13. Paul V. Tartabini, David M. Bose, Mark N. Thornblom, J. P. Lien, and John G. Martin, "Mach 10 Stage Separation Analysis for the X43-A," AIAA 2006-1038, January 2006.

14. Mark C. Davis, Joseph W. Pahle, John Terry White, Laurie A. Marshall, Michael J. Mashburn, and Rick Franks, Development of a Flush Airdata Sensing System on a Sharp-Nosed Vehicle for Flight at Mach 3 to 8, NASA/TM-2000-209017, 2000. 
15. Justus, C. G., W. R. Jeffries III, S. P. Yung, and D. L. Johnson, The NASA/MSFC Global Reference Atmospheric Model-1995 Version (GRAM-95), NASA Technical Memorandum 4715, 1995.

16. Cockrell Jr., Charles E., Walter C. Engelund, Robert D. Bittner, Tom N. Jentink, Arthur D. Dilley, and Abdelkader Frendi, "Integrated Aeropropulsive Computational Fluid Dynamics Methodology for the Hyper-X Flight Experiment," Journal of Spacecraft and Rockets, Vol. 38, No. 6, November-December 2001.

17. Redifer, Matthew, Yohan Lin, Courtney Amos Bessent, and Carole Barklow, The Hyper- $X$ Flight Systems Validation Program, NASA/TM-2007-214620, 2007.

18. Bahm, Catherine, Ethan Baumann, John Martin, David Bose, Roger E. Beck, and Brian Strovers, "The X-43A Hyper-X Mach 7 Flight 2 Guidance, Navigation, and Control Overview and Flight Test Results," AIAA 2005-3275, May 2005.

19. Baumann, Ethan, Catherine Bahm, Brian Strovers, and Roger Beck, The X-43A Mach 10 Mission Guidance and Control Updates, Rationale, and Flight Test Results, NASA/TM-2007-214610, 2007. Available from the former chief engineer, X-43 Project. 
Table 1. Monte Carlo parameters saved at 1, 10, and $100 \mathrm{~Hz}$.

\begin{tabular}{|c|c|c|c|}
\hline Description & $1 \mathrm{~Hz}$ & $10 \mathrm{~Hz}$ & $100 \mathrm{~Hz}$ \\
\hline Angle of attack & & $\mathrm{X}$ & $\mathrm{X}$ \\
\hline Sensed angle of attack & & $\mathrm{X}$ & $\mathrm{X}$ \\
\hline Angle of attack command & & $\mathrm{X}$ & $\mathrm{X}$ \\
\hline Estimated angle of attack & & $X$ & $\mathrm{X}$ \\
\hline Axial acceleration & & $\mathrm{X}$ & $X$ \\
\hline Side acceleration & & $\mathrm{X}$ & $\mathrm{X}$ \\
\hline Vertical acceleration & & $\mathrm{X}$ & $\mathrm{X}$ \\
\hline Inertial angle of sideslip & & $\mathrm{X}$ & $\mathrm{X}$ \\
\hline Angle of sideslip & & $\mathrm{X}$ & $\mathrm{X}$ \\
\hline Coefficient of drag & & $\mathrm{X}$ & \\
\hline Coefficient of lift & & $\mathrm{X}$ & \\
\hline Cowl door command & & & $\mathrm{X}$ \\
\hline Cowl door brake & & & $\mathrm{X}$ \\
\hline Left wing command & & $\mathrm{X}$ & \\
\hline Right rudder command & & $X$ & \\
\hline Right wing command & & $\mathrm{X}$ & \\
\hline Aileron command & & $\mathrm{X}$ & $\mathrm{X}$ \\
\hline Elevator command & & $X$ & $X$ \\
\hline Rudder command & & $\mathrm{X}$ & $\mathrm{X}$ \\
\hline Right rudder deflection & & $\mathrm{X}$ & $\mathrm{X}$ \\
\hline Left wing deflection & & $X$ & $X$ \\
\hline Right wing deflection & & $\mathrm{X}$ & $\mathrm{X}$ \\
\hline Estimated engine fuel to air ratio & & & $\mathrm{X}$ \\
\hline Actual engine fuel to air ratio & & & $X$ \\
\hline FADS angle of attack bias & & $X$ & $\mathrm{X}$ \\
\hline FADS dynamic pressure estimate & & $\mathrm{X}$ & $\mathrm{X}$ \\
\hline FADS valid flag & & $X$ & $\mathrm{X}$ \\
\hline Time since separation & & & $\mathrm{X}$ \\
\hline Flight path angle & & $\mathrm{X}$ & $\mathrm{X}$ \\
\hline Altitude & $\mathrm{X}$ & $X$ & $X$ \\
\hline Rudder hinge moment & & $\mathrm{X}$ & \\
\hline Left wing hinge moment & & $\mathrm{X}$ & \\
\hline Right wing hinge moment & & $\mathrm{X}$ & \\
\hline Reference altitude & $X$ & $\mathrm{X}$ & \\
\hline Normal acceleration command & & $\mathrm{X}$ & \\
\hline Geodetic latitude & $\mathrm{X}$ & & $\mathrm{X}$ \\
\hline
\end{tabular}


Table 1. Concluded.

\begin{tabular}{|c|c|c|c|}
\hline Description & $1 \mathrm{~Hz}$ & $10 \mathrm{~Hz}$ & $100 \mathrm{~Hz}$ \\
\hline Sensed latitude & & $\mathrm{X}$ & \\
\hline Sensed longitude & & $\mathrm{X}$ & \\
\hline Mach number & $\mathrm{X}$ & $\mathrm{X}$ & $\mathrm{X}$ \\
\hline Sensed Mach number & & $\mathrm{X}$ & \\
\hline Pressures, valve settings, etc. & & & $\mathrm{X}$ \\
\hline Axial acceleration & & & $\mathrm{X}$ \\
\hline Average axial acceleration & & & $\mathrm{X}$ \\
\hline Axial acceleration at $\mathrm{CG}$ & & & $\mathrm{X}$ \\
\hline Side acceleration & & & $\mathrm{X}$ \\
\hline Average side acceleration & & & $\mathrm{X}$ \\
\hline Side acceleration at $\mathrm{CG}$ & & & $\mathrm{X}$ \\
\hline Normal acceleration command & & $\mathrm{X}$ & \\
\hline Normal acceleration & & $\mathrm{X}$ & $\mathrm{X}$ \\
\hline Average normal acceleration & & & $\mathrm{X}$ \\
\hline Normal acceleration at CG & & & $\mathrm{X}$ \\
\hline Roll rate & & $\mathrm{X}$ & $\mathrm{X}$ \\
\hline Bank angle & & $\mathrm{X}$ & $\mathrm{X}$ \\
\hline Bank angle command & & $\mathrm{X}$ & $\mathrm{X}$ \\
\hline Sensed bank angle & $\mathrm{X}$ & $\mathrm{X}$ & $\mathrm{X}$ \\
\hline \multicolumn{4}{|l|}{ PID complete flag } \\
\hline \multicolumn{4}{|l|}{ PID start flag } \\
\hline Cowl door position & & & $\mathrm{X}$ \\
\hline Heading angle & & $\mathrm{X}$ & $\mathrm{X}$ \\
\hline Pitch rate & & $\mathrm{X}$ & $\mathrm{X}$ \\
\hline Dynamic pressure & $\mathrm{X}$ & $\mathrm{X}$ & $\mathrm{X}$ \\
\hline Sensed dynamic pressure & & $\mathrm{X}$ & $\mathrm{X}$ \\
\hline Yaw rate & & $\mathrm{X}$ & $\mathrm{X}$ \\
\hline Range to go & $\mathrm{X}$ & $\mathrm{X}$ & $X$ \\
\hline Pitch attitude & & $\mathrm{X}$ & $\mathrm{X}$ \\
\hline Time & $\mathrm{X}$ & $\mathrm{X}$ & $\mathrm{X}$ \\
\hline North velocity & & $\mathrm{X}$ & \\
\hline East velocity & & $\mathrm{X}$ & \\
\hline Down velocity & & $\mathrm{X}$ & \\
\hline Latitude & $\mathrm{X}$ & $\mathrm{X}$ & $\mathrm{X}$ \\
\hline Longitude & $X$ & $\mathrm{X}$ & $\mathrm{X}$ \\
\hline
\end{tabular}




\begin{tabular}{|c|c|c|c|c|c|c|c|c|c|c|c|c|c|c|c|}
\hline & 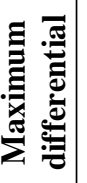 & in & - & ஜ̊ & ลे & $\bar{n}$ & 孚 & 悉 & స్రి & त्రे & $\stackrel{\infty}{\infty}$ & స్రి & $\bar{n}$ & $\hat{\alpha}$ & ठ્రે \\
\hline & $\begin{array}{l}\text { 咅 } \\
\text { 恶 }\end{array}$ & 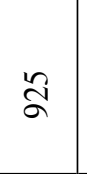 & - & $\bar{n}$ & $\frac{n}{n}$ & $\stackrel{n}{n}$ & త్రి & శ్రి & নे & $\stackrel{n}{q}$ & 字 & む̊ & ఏ్రి & శ్రి & సે \\
\hline 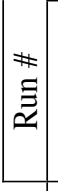 & 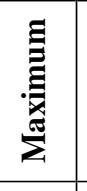 & $\sqrt{n}$ & - & দু & $\stackrel{\Xi}{\Xi}$ & $\vec{\infty}$ & 串 & : & $\sim$ & $\sim$ & $\underset{\sim}{+}$ & $\vec{n}$ & $\stackrel{\infty}{0}$ & $\ddot{0}$ & 品 \\
\hline & 竞: & $\underset{0}{J}$ & 0 & $\stackrel{f}{+}$ & $\stackrel{\varrho}{0}$ & $\tilde{ก}$ & $\stackrel{亏}{\ni}$ & $\underset{F}{F}$ & $\begin{array}{l}\stackrel{n}{\infty} \\
\infty \\
\infty\end{array}$ & $\stackrel{?}{\stackrel{2}{\sim}}$ & $\stackrel{\mathfrak{o}}{\hat{\sigma}}$ & $\tilde{\tilde{\sigma}}$ & $\stackrel{ \pm}{\stackrel{I}{S}}$ & $\stackrel{\vartheta}{\stackrel{9}{S}}$ & $\stackrel{n}{i}$ \\
\hline & 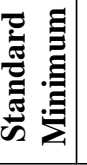 & $\stackrel{\infty}{-}$ & 0 & $\stackrel{\text { I }}{=}$ & $\stackrel{+}{\tilde{O}}$ & $\stackrel{\Im}{\stackrel{f}{0}}$ & $\begin{array}{l}\infty \\
\infty \\
0\end{array}$ & $\begin{array}{l}\infty \\
\infty \\
0 \\
0\end{array}$ & 营 & $\stackrel{+}{ \pm}$ & $\stackrel{\infty}{=}$ & $\vec{m}$ & $\stackrel{\infty}{\infty}$ & $\stackrel{\infty}{\infty}$ & $\stackrel{\circ}{-}$ \\
\hline & 总范 & $\stackrel{\check{c}}{\mathrm{i}}$ & 0 & $\stackrel{3}{i}$ & $\begin{array}{c}\hat{i} \\
\dot{i}\end{array}$ & $\underset{+}{\stackrel{ \pm}{\longrightarrow}}$ & $\overrightarrow{\widetilde{i}}$ & $\overrightarrow{\widetilde{a}}$ & în & m़? & $\underset{+}{\dot{+}}$ & \begin{tabular}{l}
$\infty$ \\
\hdashline \\
\end{tabular} & $\begin{array}{l}\infty \\
\stackrel{\infty}{+} \\
+\end{array}$ & $\stackrel{a}{a}$ & $\stackrel{d}{\Delta}$ \\
\hline & 声 & $\stackrel{\infty}{\stackrel{\infty}{+}}$ & 0 & $\underset{\overbrace{}}{\stackrel{\sim}{r}}$ & 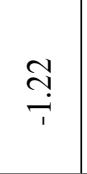 & $\begin{array}{l}\widehat{\infty} \\
i \\
i\end{array}$ & $\stackrel{8}{=}$ & $\stackrel{\circ}{\Rightarrow}$ & 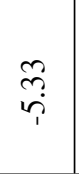 & $\vec{z}$ & $\frac{n}{r}$ & $\begin{array}{c}\tilde{r} \\
\tilde{r}\end{array}$ & $\begin{array}{l}8 \\
\stackrel{0}{0} \\
\div\end{array}$ & $\stackrel{\infty}{\stackrel{\varrho}{=}}$ & $\stackrel{n}{\stackrel{n}{+}}$ \\
\hline & 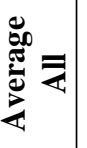 & W艹 & 0 & గొ & $\begin{array}{l}0 \\
? \\
i \\
i\end{array}$ & 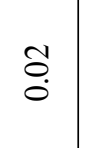 & $\vec{\jmath}$ & $\bar{~}$ & $\underset{i}{\stackrel{N}{i}}$ & 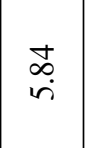 & $\stackrel{1}{0}$ & $\mid \begin{array}{c}\infty \\
i \\
i\end{array}$ & $\stackrel{0}{0}$ & $\stackrel{8}{0}$ & 官 \\
\hline & 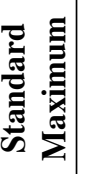 & $\stackrel{\infty}{i}$ & 0 & $\stackrel{n}{i}$ & $\begin{array}{l}n \\
o \\
o\end{array}$ & $\stackrel{\stackrel{\Im}{\circ}}{0}$ & $\stackrel{\infty}{\stackrel{\infty}{-}}$ & 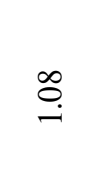 & 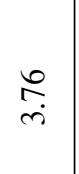 & $\underset{\text { ț }}{\stackrel{t}{0}}$ & $\stackrel{t}{o}$ & 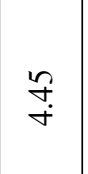 & $\bar{a}$ & $\stackrel{\infty}{\circ}$ & $\begin{array}{l}\infty \\
\infty \\
\stackrel{\infty}{\infty}\end{array}$ \\
\hline & 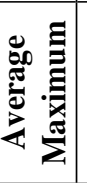 & $\stackrel{m}{=}$ & 0 & $\stackrel{\text { Iิ }}{\stackrel{0}{\subseteq}}$ & $\begin{array}{c}\bar{N} \\
\dot{\varphi}\end{array}$ & $\exists$ & $\begin{array}{l}\stackrel{\partial}{\not} \\
\infty \\
\infty\end{array}$ & $\stackrel{\infty}{\infty}$ & $\begin{array}{l}\underset{t}{0} \\
\stackrel{0}{0}\end{array}$ & $\underset{\hat{\theta}}{\stackrel{R}{6}}$ & $\stackrel{\infty}{\stackrel{+}{+}}$ & $\ddot{\ddot{\sigma}}$ & $\stackrel{\infty}{\circ}$ & 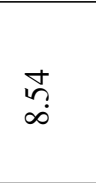 & $\begin{array}{l}\underset{⿱}{+} \\
\stackrel{0}{\oplus}\end{array}$ \\
\hline & 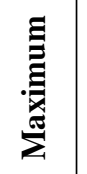 & $\begin{array}{l}\vec{D} \\
\stackrel{b}{n}\end{array}$ & 0 & 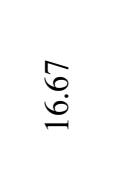 & $\begin{array}{l}0 \\
\dot{i}\end{array}$ & $\stackrel{B}{r}$ & 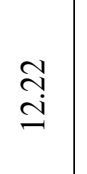 & $\begin{array}{l}\text { İ } \\
\text { Int }\end{array}$ & तi & ते & $\stackrel{+}{\stackrel{r}{r}}$ & $\dot{\vec{\lambda}}$ & $\underset{\infty}{\stackrel{\infty}{\infty}}$ & $\stackrel{\leftrightarrow}{=}$ & $\stackrel{m}{\sim}$ \\
\hline & $\stackrel{n}{:}$ & $\stackrel{\infty}{0}$ & $\stackrel{\infty}{0}$ & 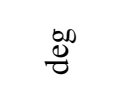 & 0 & $\stackrel{\infty}{\oplus}$ & $\stackrel{\infty}{0}$ & 践 & $\stackrel{\infty}{0}$ & $\stackrel{80}{0}$ & $\stackrel{\infty}{\infty}$ & $\stackrel{\infty}{\mathbb{0}}$ & $\stackrel{\infty}{0}$ & $\frac{80}{8}$ & $\stackrel{\infty}{\oplus}$ \\
\hline & 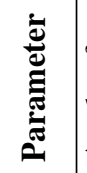 & 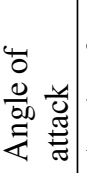 & 岁 & 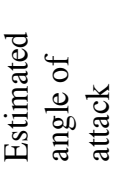 & 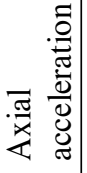 & 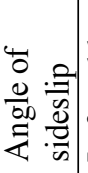 & 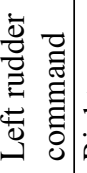 & 总部 & हี & 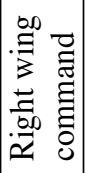 & 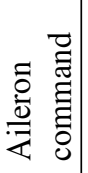 & 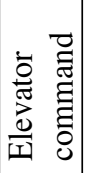 & & 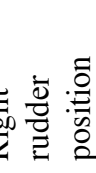 & 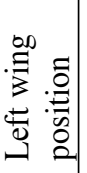 \\
\hline
\end{tabular}




\begin{tabular}{|c|c|c|c|c|c|c|c|c|c|c|c|c|c|c|c|c|c|}
\hline 量 & ठิర & $\stackrel{\infty}{\infty}$ & Әิ & $\hat{8}$ & $\vec{\infty}$ & त్రి & ¿ิ & $\sqrt{n}$ & 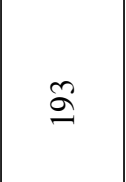 & ำ & స్రి & ฉั & Әे & ஃొర & & q & $\mathscr{\vartheta}$ \\
\hline 音 & \&ু & જิ & I & ત్రి & $\stackrel{2}{I}$ & ลे & बे & ơ & 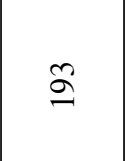 & $\bar{n}$ & Әे & fo & बे & 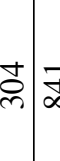 & $\overline{0}$ & ৯े & Бे \\
\hline 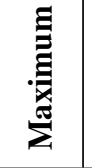 & $\stackrel{\infty}{\sim}$ & $\bar{\infty}$ & $\bar{\sigma}$ & $\stackrel{\infty}{0}$ & $\hat{8}$ & ఫ్రి & స్రે & ஓ & $\cong$ & $\bar{n}$ & స్రి & \& & & : & $\begin{array}{l}8 \\
0 \\
n\end{array}$ & $\Phi$ & $\stackrel{\vartheta}{\forall}$ \\
\hline 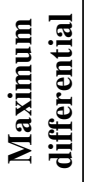 & $\stackrel{\sim}{\sim}$ & $\stackrel{\mathbb{Z}}{\tilde{0}}$ & $\stackrel{\infty}{\underset{i}{i}}$ & $\stackrel{?}{\stackrel{2}{r}}$ & $\stackrel{\overbrace{}}{\leftrightarrows}$ & $\stackrel{n}{g}$ & $\stackrel{2}{2}$ & $\stackrel{\overbrace{}}{0}$ & $n$ & $\stackrel{+}{\stackrel{+}{0}}$ & $=$ & $\stackrel{?}{\circ}$ & $\mid \begin{array}{c}\sigma \\
\tilde{m} \\
\ddots\end{array}$ & $\begin{array}{c}\infty \\
\substack{\infty\\
}\end{array}$ & & ְ. & $\begin{array}{l}\text { ले } \\
\ddot{f}\end{array}$ \\
\hline 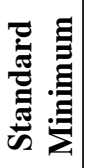 & $\stackrel{0}{+}$ & $\stackrel{ \pm}{ت}$ & $\stackrel{n}{n}$ & 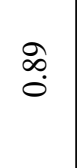 & $\stackrel{8}{0}$ & $\stackrel{5}{0}$ & $\stackrel{9}{\overrightarrow{0}}$ & $\stackrel{\infty}{\stackrel{n}{r}}$ & $\stackrel{0}{0}$ & $\stackrel{m}{0}$ & 客 & $\stackrel{\infty}{\infty}$ & $\begin{array}{c}\tilde{\sigma} \\
\dot{\gamma} \\
\dot{\gamma}\end{array}$ & & & $\begin{array}{l}\stackrel{m}{r} \\
\infty \\
0 \\
i\end{array}$ & $\stackrel{n}{n}$ \\
\hline 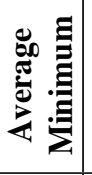 & $\stackrel{\widehat{\vartheta}}{\circ}$ & $\frac{n}{\dot{r}}$ & $\vec{J}$ & $\frac{c}{a}$ & $\stackrel{\text { in }}{i}$ & $\begin{array}{l}\stackrel{t}{0} \\
\stackrel{9}{9}\end{array}$ & $\begin{array}{l}\infty \\
0 \\
0 \\
\dot{1}\end{array}$ & $\begin{array}{l}\infty \\
\stackrel{\infty}{i} \\
\stackrel{r}{r}\end{array}$ & ?ొ & 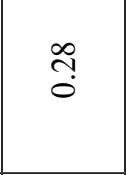 & $\left|\begin{array}{c}\widetilde{N} \\
\stackrel{2}{r} \\
\end{array}\right|$ & 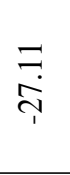 & $\mid \begin{array}{c}c \\
0 \\
\dot{t} \\
\dot{t} \\
1\end{array}$ & 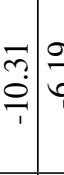 & & 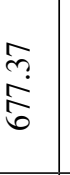 & 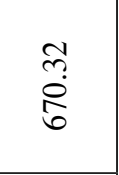 \\
\hline 䒠 & $\begin{array}{l}\bar{\infty} \\
\dot{+}\end{array}$ & $\underset{n}{\stackrel{n}{r}}$ & 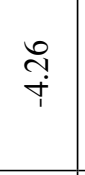 & 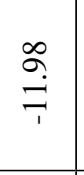 & $\stackrel{\text { oे }}{\rightarrow}$ & $\underset{i}{\stackrel{?}{\rightarrow}}$ & & $\begin{array}{l}\stackrel{n}{a} \\
\stackrel{n}{n}\end{array}$ & $\tilde{n}$ & $\begin{array}{l}\text { gे } \\
\text { i }\end{array}$ & $\mid \begin{array}{c}\tilde{\omega} \\
\tilde{\sigma} \\
\tilde{\gamma}\end{array}$ & $\begin{array}{l}\widehat{6} \\
\dot{+} \\
\dot{1}\end{array}$ & 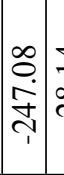 & 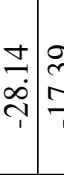 & ?. & $\begin{array}{l}\text { ळे } \\
\text { ळે }\end{array}$ & $\begin{array}{l}\text { ते } \\
\text { ते }\end{array}$ \\
\hline 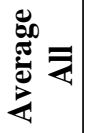 & ¿. & $\stackrel{\vartheta}{0}$ & 0 & $\stackrel{8}{\circ}$ & 0 & 0 & 0 & $\ddot{r}$ & ڤे & $\stackrel{0}{0}$ & 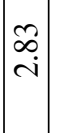 & $=$ & $\mid \begin{array}{ll}0 & 0 \\
0 & 0 \\
& 0\end{array}$ & 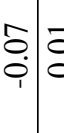 & $\vec{b}$ & 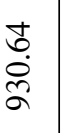 & $\begin{array}{l}\stackrel{\circ}{\stackrel{d}{J}} \\
\text { a }\end{array}$ \\
\hline 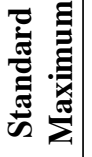 & $\stackrel{ }{\dot{m}}$ & $\begin{array}{l}\infty \\
\infty \\
0\end{array}$ & $\stackrel{\check{a}}{\grave{r}}$ & $\stackrel{\infty}{\circ}$ & $\stackrel{8}{\circ}$ & $\stackrel{\infty}{\square}$ & $\stackrel{\circ}{\circ}$ & $\begin{array}{l}\bar{\infty} \\
0 \\
0\end{array}$ & $\stackrel{\infty}{\circ}$ & ले & $\begin{array}{l}\Delta \\
2 \\
2\end{array}$ & 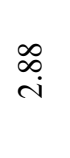 & $\mid \begin{array}{c}\mathcal{J} \\
\vec{I} \\
\dot{f}\end{array}$ & $\frac{a}{6} \mid \vec{x}$ & i. & 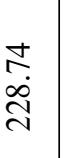 & ঐิ \\
\hline 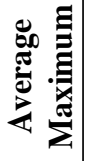 & 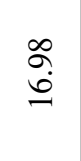 & $\stackrel{\imath}{\stackrel{f}{+}}$ & $\stackrel{\infty}{+}$ & $\begin{array}{l}\text { Hn } \\
\infty\end{array}$ & ڤึ? & $\begin{array}{l}\tilde{\sigma} \\
0 \\
0\end{array}$ & $\begin{array}{l}\hat{0} \\
0\end{array}$ & $\frac{n}{0}$ & $\sim$ & $\stackrel{\circ}{\stackrel{2}{-}}$ & 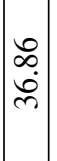 & $\stackrel{\circ}{\circ}$ & $\mid \begin{array}{l}0 \\
\vdots \\
\infty \\
\infty \\
i\end{array}$ & 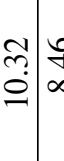 & : & 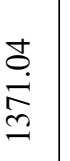 & $\begin{array}{l}\vec{\infty} \\
\stackrel{a}{\sigma} \\
\stackrel{0}{\omega}\end{array}$ \\
\hline 䒠 & $\stackrel{\stackrel{d}{\sim}}{\stackrel{\sim}{N}}$ & $\stackrel{\infty}{\underset{1}{\sim}}$ & $\stackrel{\vartheta}{\stackrel{\vec{\lambda}}{\vec{d}}}$ & $\stackrel{\circ}{\varrho}$ & $\stackrel{શ}{\stackrel{\overbrace{}}{-}}$ & 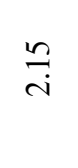 & तु & $\stackrel{\curvearrowright}{\infty}$ & $\tilde{n}$ & $\begin{array}{l}0 \\
i n \\
n\end{array}$ & $\begin{array}{l}\infty \\
\dot{8} \\
0\end{array}$ & $\stackrel{\infty}{\stackrel{0}{0}}$ & $\left|\begin{array}{c}m \\
f \\
\dot{0} \\
0 \\
0\end{array}\right|$ & 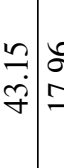 & : & $\begin{array}{l}\hat{\sigma} \\
\dot{+} \\
\hat{c}\end{array}$ & 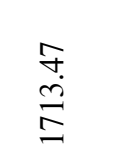 \\
\hline 负 & 安 & 我 & 我 & $\begin{array}{l}50 \\
8 \\
\end{array}$ & $\begin{array}{l}\frac{\infty}{80} \\
\frac{8}{8}\end{array}$ & $\begin{array}{l}\frac{n}{50} \\
\frac{8}{0}\end{array}$ & $\begin{array}{l}\frac{n}{600} \\
\frac{\delta}{g}\end{array}$ & 我 & ט & ט & $\mid \begin{array}{l}\mid 00 \\
0 \\
0\end{array}$ & 80 & $\left|\begin{array}{c}\frac{n}{80} \\
\frac{8}{0}\end{array}\right|$ & \begin{tabular}{c|c}
$\frac{n}{b 00}$ \\
$\frac{\delta 0}{c}$
\end{tabular} & $\begin{array}{c}c \\
0 \\
0 \\
0\end{array}$ & $\overleftrightarrow{\widetilde{2}}$ & 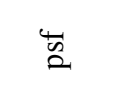 \\
\hline 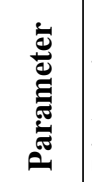 & 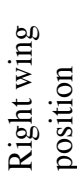 & 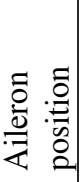 & 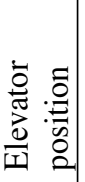 & 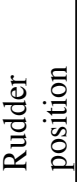 & 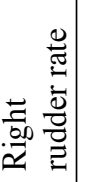 & 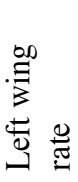 & 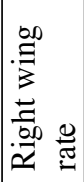 & 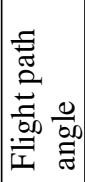 & 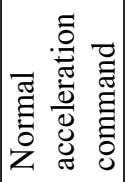 & 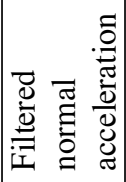 & 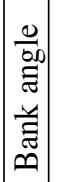 & 氧: & 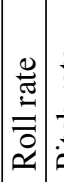 & 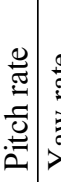 & & 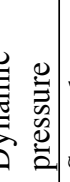 & 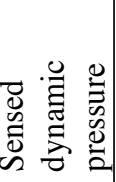 \\
\hline
\end{tabular}




\begin{tabular}{|c|c|c|c|c|c|c|c|c|c|}
\hline 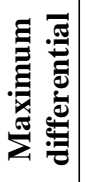 & $\bar{m}$ & $\stackrel{\infty}{\stackrel{\infty}{1}}$ & $\underset{\infty}{\tilde{\infty}}$ & ৯े & ల & જ̆ & ঠ্ల & $\bar{n}$ & $\bar{n}$ \\
\hline$\underset{\mathrm{E}}{\mathrm{\Xi}}$ & 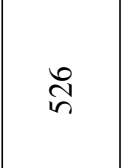 & \& & ৪ & $\begin{array}{l}\infty \\
\stackrel{ల}{\infty}\end{array}$ & $\hat{n}$ & స్రి & \& & ঃั & $\frac{\pi}{\sigma}$ \\
\hline 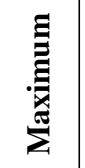 & - & \& & $\stackrel{\infty}{\stackrel{\sim}{\sigma}}$ & 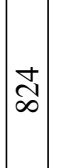 & $\stackrel{+}{\infty}$ & જ̆ & $\stackrel{\circ}{+}$ & \&్ల & $\infty$ \\
\hline 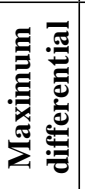 & $\stackrel{?}{=}$ & 0 & $\stackrel{\Xi}{0}$ & $\mathrm{~N}$ & $\stackrel{\circ}{\circ}$ & $\stackrel{\vartheta}{\forall}$ & : & 0 & ळे \\
\hline 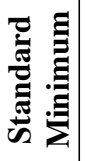 & 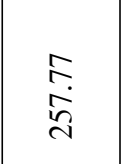 & $\stackrel{ \pm}{0}$ & $\underset{0}{ \pm}$ & - & $\stackrel{\infty}{0}$ & $\stackrel{0}{\circ}$ & $\begin{array}{l}+ \\
\infty \\
i\end{array}$ & $\stackrel{0}{0}$ & 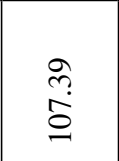 \\
\hline 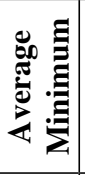 & $\frac{\Omega}{\sigma}$ & $\begin{array}{c}\stackrel{\infty}{0} \\
\stackrel{0}{0}\end{array}$ & $\ddot{0}$ & 0 & $\stackrel{\sim}{\sim}$ & त̂. & $\begin{array}{l}\infty \\
\infty \\
\infty \\
\infty\end{array}$ & 仓̊. & $\begin{array}{l}\stackrel{9}{0} \\
\infty \\
\infty\end{array}$ \\
\hline$\underset{\mathrm{E}}{\mathrm{E}}$ & 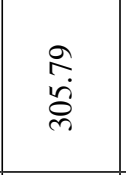 & \begin{tabular}{l}
0 \\
\multirow{0}{0}{} \\
0
\end{tabular} & $\stackrel{0}{+}$ & † & $\stackrel{゚}{\stackrel{\gtrless}{+}}$ & ra & $\underset{\frac{0}{6}}{\stackrel{0}{6}}$ & $\frac{a}{\dot{\varphi}}$ & $\begin{array}{l}n \\
n \\
\infty \\
n \\
n \\
1\end{array}$ \\
\hline 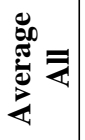 & $\begin{array}{l}\stackrel{+}{n} \\
\stackrel{0}{0} \\
=\end{array}$ & $\underset{m}{\stackrel{\infty}{f}}$ & $\stackrel{\infty}{\stackrel{m}{+}}$ & $\frac{\infty}{8}$ & $\stackrel{\text { ô }}{\stackrel{\varphi}{\varphi}}$ & $\stackrel{\widehat{\vartheta}}{i}$ & $\underset{T}{\sigma}$ & 0 & $\begin{array}{l}\infty \\
\infty \\
i\end{array}$ \\
\hline 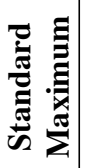 & 0 & $\overrightarrow{0}$ & 0 & ૂิ & 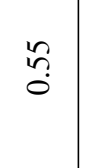 & $\begin{array}{l}\infty \\
\infty \\
\stackrel{0}{0}\end{array}$ & $\underset{\infty}{\stackrel{\Delta}{0}}$ & $\stackrel{n}{0}$ & $\begin{array}{l}\hat{\sigma} \\
\stackrel{0}{0}\end{array}$ \\
\hline 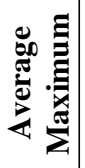 & ষి & $\hat{a}$ & $\infty$ & 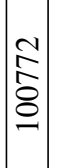 & $\vec{\sigma}$ & 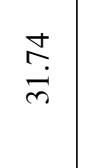 & $\vec{i}$ & $\overrightarrow{0}$ & $\hat{\stackrel{\sigma}{\sigma}}$ \\
\hline 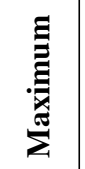 & ఫి & $\begin{array}{l}\hat{y} \\
\infty\end{array}$ & $\infty$ & $\begin{array}{l}\frac{\infty}{\sim} \\
\widetilde{\Omega} \\
0\end{array}$ & $\stackrel{n}{n}$ & $\begin{array}{l}\circ \\
\infty \\
\alpha\end{array}$ & $\begin{array}{l}n \\
\hat{\infty} \\
i n\end{array}$ & $\begin{array}{l}\stackrel{\infty}{\leftrightarrow} \\
\stackrel{0}{0}\end{array}$ & 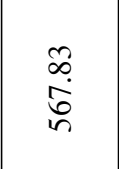 \\
\hline$\stackrel{\mathscr{B}}{\mathrm{g}}$ & $\ddot{\breve{a}}$ & $\stackrel{\pi}{\Omega}$ & $\stackrel{\Xi}{\beth}$ & $=$ & $\frac{80}{8}$ & 車 & 我 & $\stackrel{\pi}{\Xi}$ & $\overrightarrow{\breve{a}}$ \\
\hline : & 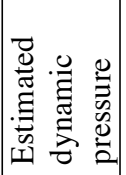 & 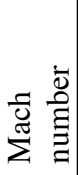 & 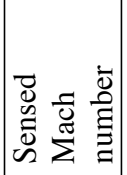 & 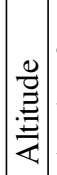 & 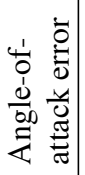 & 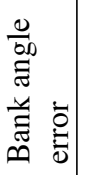 & 总 & 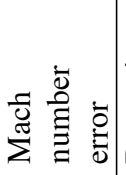 & 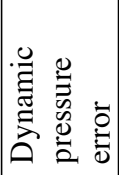 \\
\hline
\end{tabular}


Table 3. Monte Carlo uncertainty models and summary of parameters varied.

\begin{tabular}{|c|c|c|c|}
\hline Uncertainty model & $\begin{array}{l}\text { Number of } \\
\text { parameters }\end{array}$ & Parameters varied & $\begin{array}{l}\text { Uncertainty } \\
\text { distribution }\end{array}$ \\
\hline Separation condition & 12 & $\begin{array}{c}\text { Angle of attack, angle of } \\
\text { sideslip, altitude, longitude, } \\
\text { latitude, Mach number, } \\
\text { attitude angles, angular rates }\end{array}$ & Uniform \\
\hline Mass properties & 8 & $\begin{array}{l}\text { Center of gravity position, } \\
\text { moments of inertia, weight }\end{array}$ & Uniform \\
\hline $\begin{array}{l}\text { Control surface } \\
\text { actuator performance }\end{array}$ & 66 & $\begin{array}{l}\text { Actuator performance } \\
\text { parameters for the } 2 \text { all- } \\
\text { moving wings and the } \\
2 \text { rudders }\end{array}$ & Uniform \\
\hline HXRV aerodynamics & 17 & $\begin{array}{c}\text { Aerodynamic coefficients } \\
\text { and biases }\end{array}$ & Gaussian \\
\hline $\begin{array}{l}\text { Separation } \\
\text { aerodynamics }\end{array}$ & 9 & $\begin{array}{c}\text { Scale factors on separation } \\
\text { aerodynamics deltas }\end{array}$ & Uniform \\
\hline $\begin{array}{l}\text { Piston performance } \\
\text { (separation) }\end{array}$ & 7 & Piston performance terms & Uniform \\
\hline $\begin{array}{l}\text { Flush airdata system } \\
\text { (FADS) }\end{array}$ & 8 & $\begin{array}{c}\text { Pressure port } \mathrm{CP} \text { and } \\
\text { measurement uncertainty }\end{array}$ & Uniform \\
\hline $\begin{array}{l}\text { Atmospheric } \\
\text { conditions }\end{array}$ & 1 & Month & Uniform \\
\hline \multirow{4}{*}{ Winds } & 12 & Altitude $(10-120) \mathrm{kft}$ & Uniform \\
\hline & 12 & Horizontal speed & Uniform \\
\hline & 12 & Wind direction & Uniform \\
\hline & 12 & Vertical wind velocity & Uniform \\
\hline \multirow{3}{*}{ Sensors } & 51 & Gyro error and bias terms & Uniform \\
\hline & 42 & $\begin{array}{c}\text { Accelerometer error and bias } \\
\text { terms }\end{array}$ & Uniform \\
\hline & 12 & $\begin{array}{l}\text { INS initialization and } \\
\text { misalignment errors }\end{array}$ & Uniform \\
\hline Engine performance & 1 & Engine performance scalar & Uniform \\
\hline $\begin{array}{l}\text { Propulsion } \\
\text { performance }\end{array}$ & 4 & $\begin{array}{c}\text { Propulsion performance } \\
\text { parameters }\end{array}$ & Uniform \\
\hline \multicolumn{4}{|l|}{$\begin{array}{l}\text { Total number of } \\
\text { parameters }\end{array}$} \\
\hline
\end{tabular}




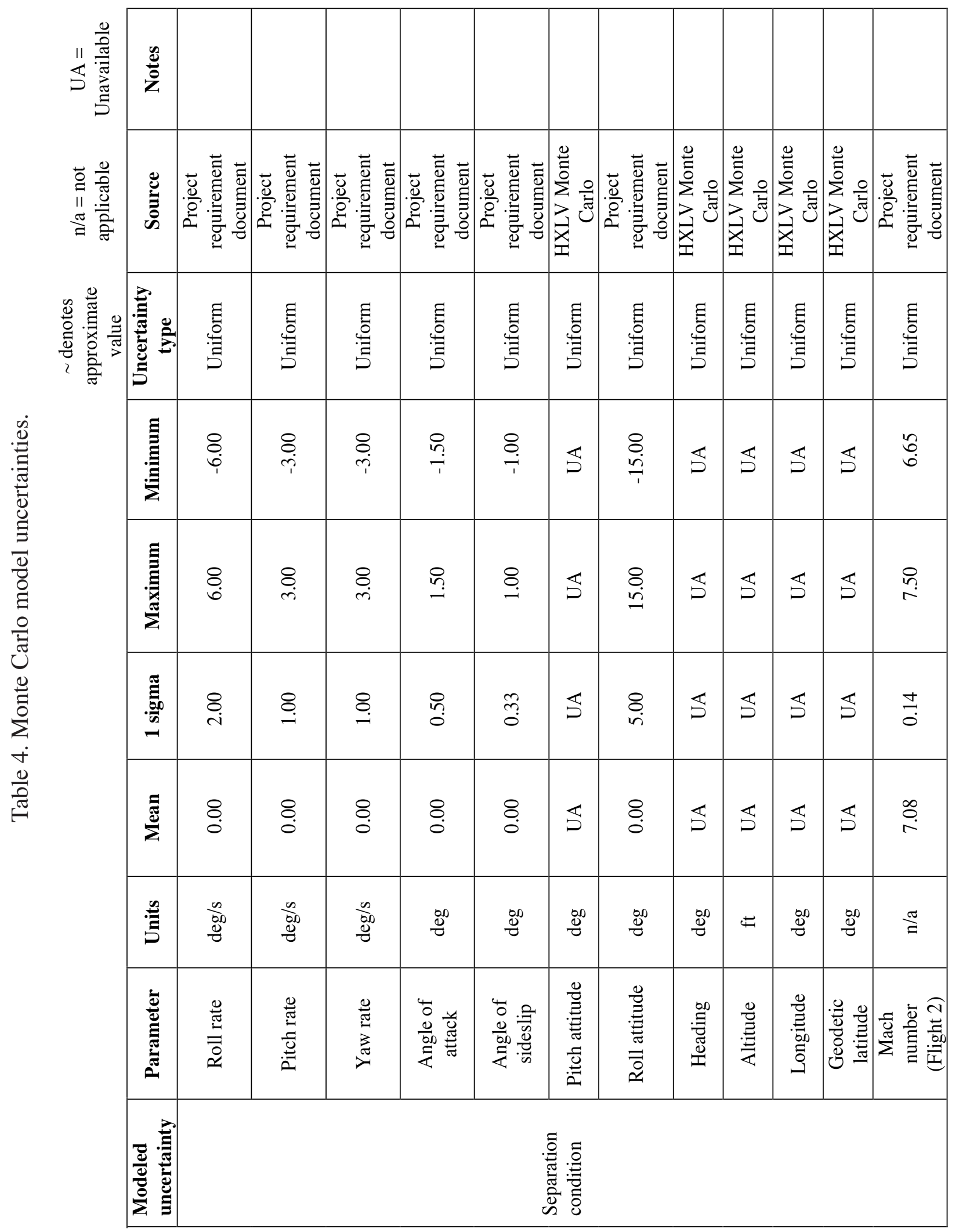




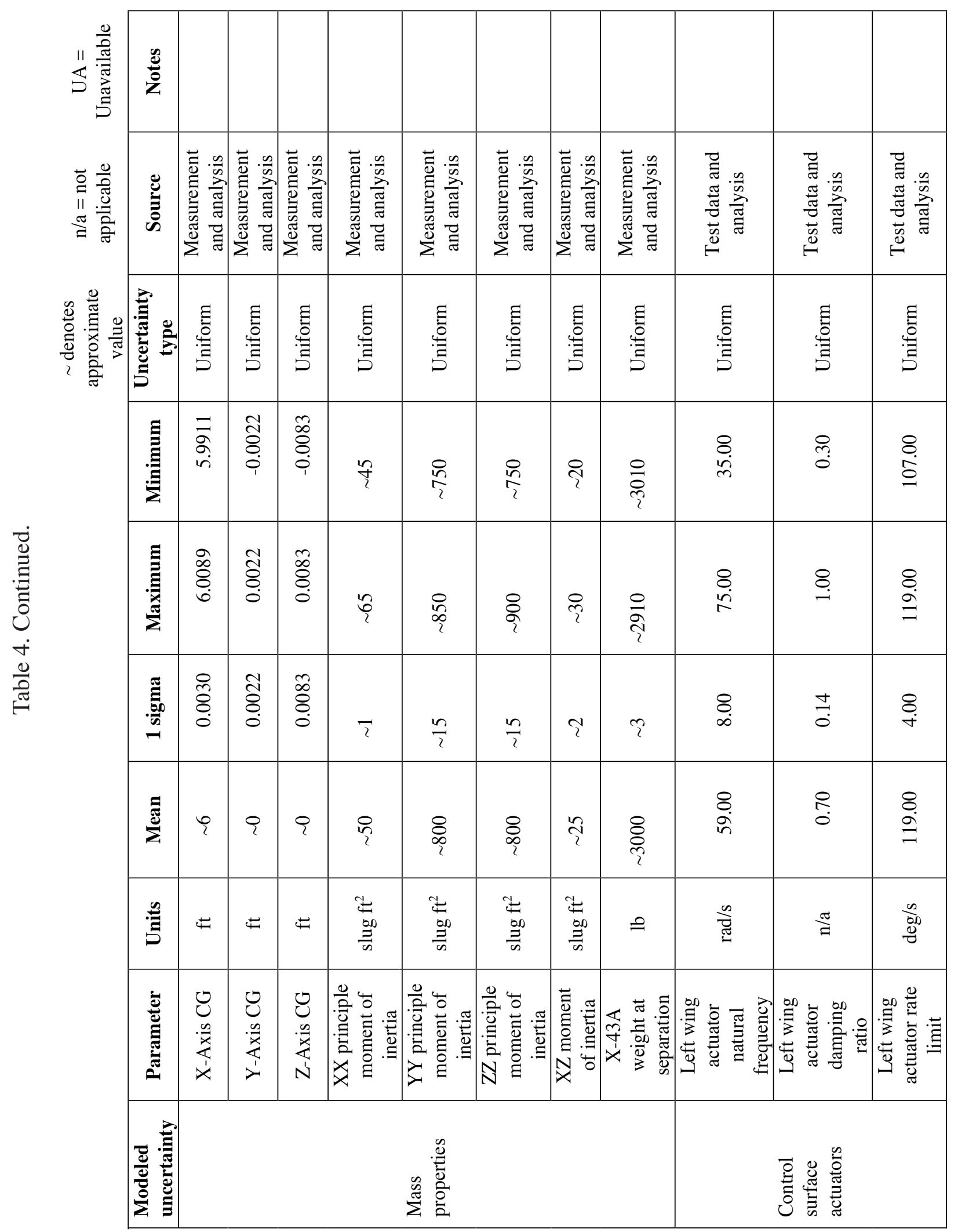




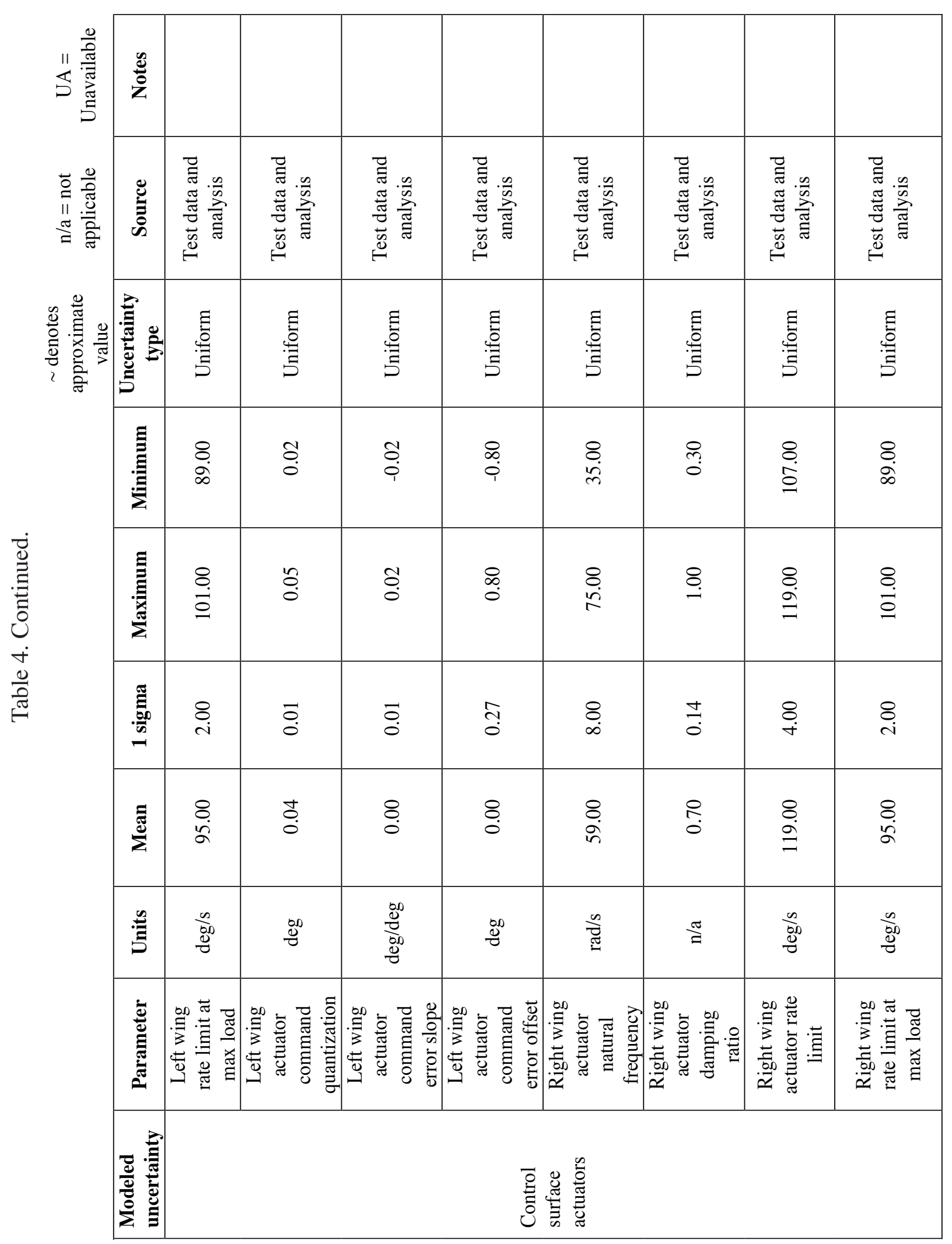




\begin{tabular}{|c|c|c|c|c|c|c|c|c|c|}
\hline 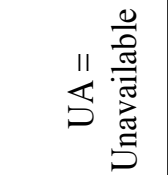 & $\frac{0}{\frac{0}{0}}$ & & & & & & & & \\
\hline 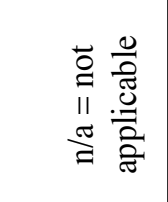 & 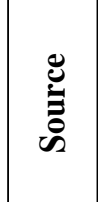 & 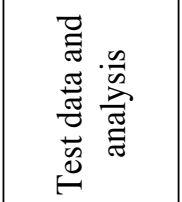 & 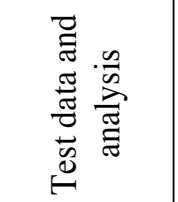 & 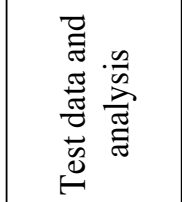 & 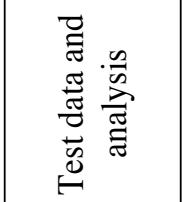 & 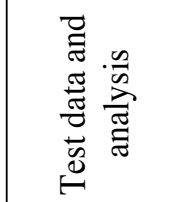 & 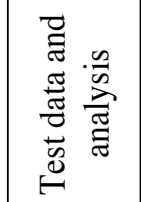 & 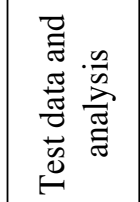 & 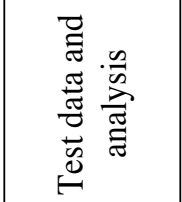 \\
\hline 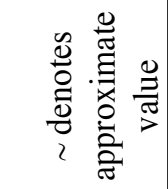 & 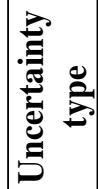 & 苛 & 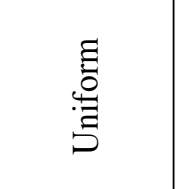 & 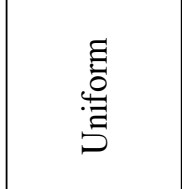 & $\begin{array}{l}\Xi \\
.00 \\
:\end{array}$ & $\begin{array}{l}\Xi \\
\stackrel{0}{0} \\
\text { : }\end{array}$ & $\stackrel{\Xi}{\Xi}$ & 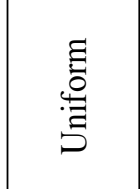 & 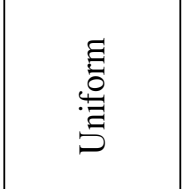 \\
\hline & 䒠 & ठ઼. & $\begin{array}{l}\text { O̦. } \\
\stackrel{+}{Q}\end{array}$ & $\begin{array}{l}\infty \\
\infty \\
\dot{\varphi}\end{array}$ & $\begin{array}{l}8 \\
\ddot{m} \\
\ddot{m}\end{array}$ & ণ্ণি & $\begin{array}{l}8 \\
\frac{8}{0}\end{array}$ & $\begin{array}{l}8 \\
\stackrel{\infty}{ }\end{array}$ & $\stackrel{\text { ô. }}{0}$ \\
\hline & 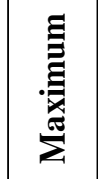 & $\stackrel{n}{0}$ & $\stackrel{0}{0}$ & $\begin{array}{l}\infty \\
0 \\
0\end{array}$ & $\underset{8}{8}$ & $\underset{-}{8}$ & $\begin{array}{l}8 \\
\stackrel{8}{\Xi}\end{array}$ & $\begin{array}{l}8 \\
\stackrel{8}{0}\end{array}$ & $\stackrel{n}{0}$ \\
\hline & 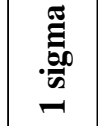 & $\stackrel{\Xi}{0}$ & $\stackrel{\Xi}{0}$ & ઼ָ & $\underset{\infty}{\infty}$ & $\stackrel{ \pm}{0}$ & $\underset{+}{\stackrel{\leftrightarrow}{+}}$ & $\underset{i}{\stackrel{8}{i}}$ & $\stackrel{\sigma}{0}$ \\
\hline & $\sum^{\tilde{E}}$ & $\stackrel{+}{0}$ & $\stackrel{8}{\circ}$ & $\stackrel{8}{8}$ & $\begin{array}{l}8 \\
\text { in }\end{array}$ & $\stackrel{尺}{\circ}$ & $\begin{array}{l}8 \\
\stackrel{8}{=}\end{array}$ & 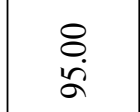 & $\underset{0}{\stackrel{\Delta}{0}}$ \\
\hline & 莺 & $\frac{00}{8}$ & $\begin{array}{l}\frac{00}{20} \\
\frac{0}{200} \\
\frac{8}{0}\end{array}$ & $\stackrel{800}{8}$ & $\sum_{\tilde{I}}^{\infty}$ & $\stackrel{\widetilde{\Omega}}{\Xi}$ & $\begin{array}{l}\frac{n}{800} \\
\frac{8}{0}\end{array}$ & $\frac{n}{800} \frac{0}{0}$ & D) \\
\hline & 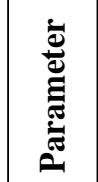 & 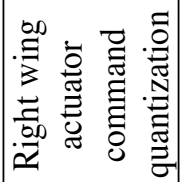 & 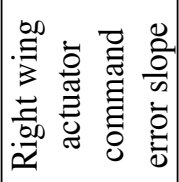 & 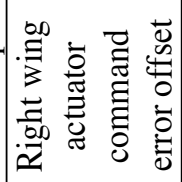 & 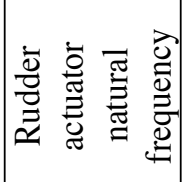 & 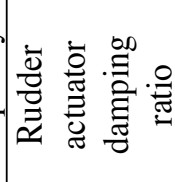 & 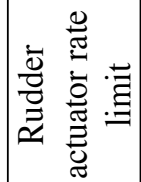 & 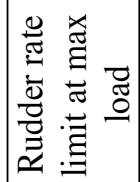 & 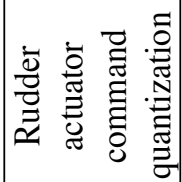 \\
\hline & 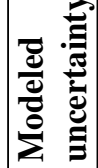 & \multicolumn{8}{|c|}{ 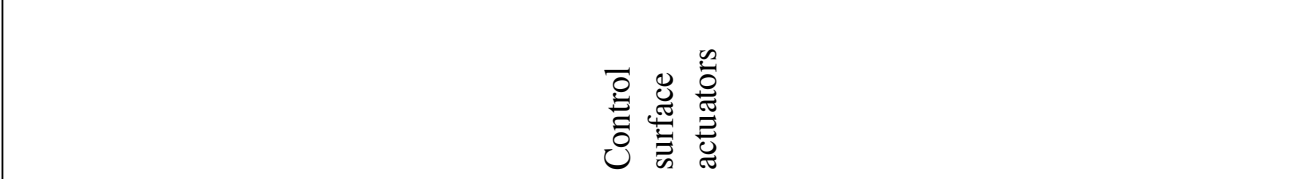 } \\
\hline
\end{tabular}




\begin{tabular}{|c|c|c|c|c|c|c|c|c|c|c|}
\hline 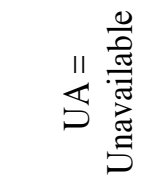 & हैँ & & & 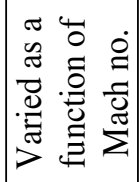 & 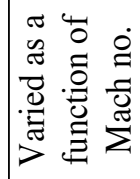 & 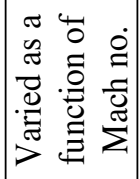 & 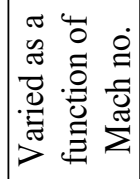 & 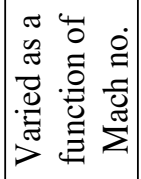 & 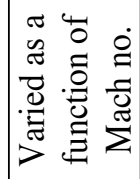 & \\
\hline 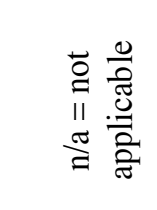 & 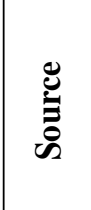 & 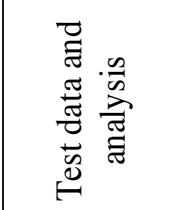 & 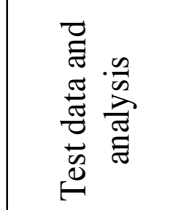 & 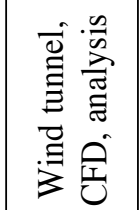 & 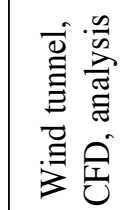 & 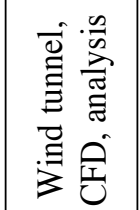 & 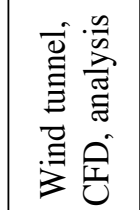 & 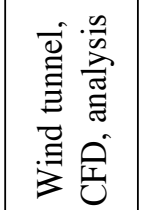 & 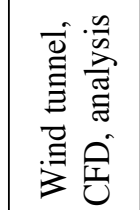 & 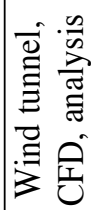 \\
\hline 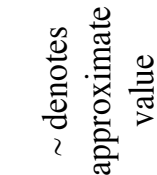 & 尝 & 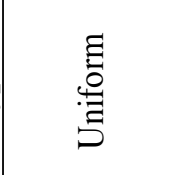 & 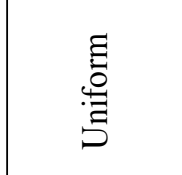 & 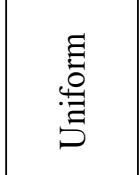 & 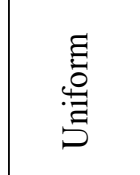 & 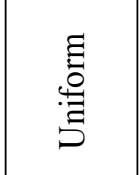 & 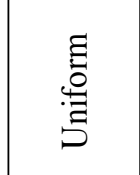 & 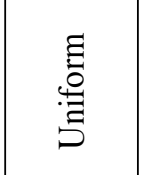 & $\begin{array}{l}\Xi \\
\stackrel{0}{0} \\
:\end{array}$ & 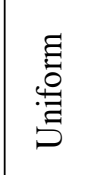 \\
\hline & 志 & 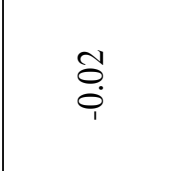 & $\begin{array}{l}\stackrel{0}{0} \\
\stackrel{1}{1}\end{array}$ & 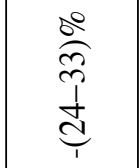 & 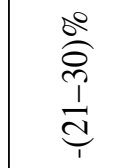 & 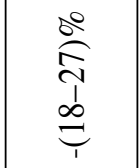 & $\begin{array}{l}\stackrel{0}{O} \\
\frac{1}{1} \\
\frac{1}{1}\end{array}$ & 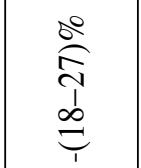 & $\begin{array}{l}\stackrel{0}{O} \\
\frac{1}{d} \\
\frac{1}{1}\end{array}$ & $\overleftrightarrow{口}$ \\
\hline & 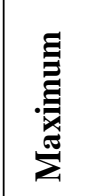 & $\stackrel{\text { ô. }}{0}$ & $\begin{array}{l}\infty \\
\infty \\
0\end{array}$ & 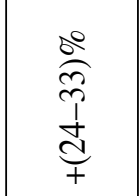 & 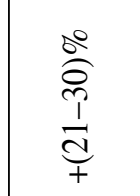 & 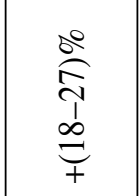 & $\begin{array}{l}\stackrel{0}{0} \\
\stackrel{0}{1} \\
\frac{a}{+} \\
+\end{array}$ & 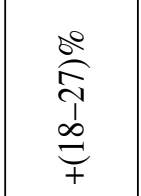 & $\begin{array}{l}\stackrel{0}{0} \\
\stackrel{0}{1} \\
\frac{1}{2} \\
+\end{array}$ & $\overleftrightarrow{\triangleright}$ \\
\hline & 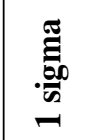 & $\ddot{0}$ & ઼ָ & $\frac{\stackrel{0}{\Xi}}{\overbrace{0}^{\prime}}$ & $\frac{\stackrel{\circ}{a}}{\frac{1}{c}}$ & $\frac{\stackrel{a}{a}}{\hat{d}}$ & $\frac{\stackrel{0}{0}}{\frac{1}{c}}$ & $\frac{\stackrel{d}{a}}{\hat{d}}$ & $\frac{\stackrel{0}{0}}{\frac{1}{2}}$ & $\overleftrightarrow{口}$ \\
\hline & $\stackrel{\mathbb{E}}{\bar{E}}^{\bar{E}}$ & $\stackrel{8}{0}$ & $\stackrel{8}{0}$ & 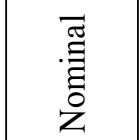 & 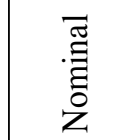 & $\begin{array}{l}\text { 吕 } \\
\text { 己े }\end{array}$ & 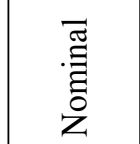 & 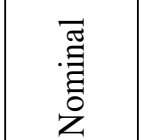 & 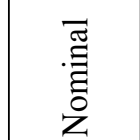 & 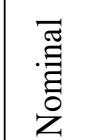 \\
\hline & 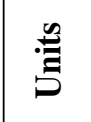 & $\begin{array}{l}\frac{80}{80} \\
\frac{8}{00} \\
\frac{8}{0}\end{array}$ & D & $\stackrel{\pi}{\Xi}$ & $\stackrel{\pi}{\Xi}$ & $\stackrel{\pi}{\Xi}$ & $\stackrel{\mathscr{a}}{=}$ & $\stackrel{\pi}{\Xi}$ & $\stackrel{\pi}{\Xi}$ & $\stackrel{\Xi}{\Omega}$ \\
\hline & 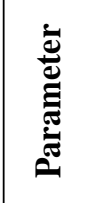 & 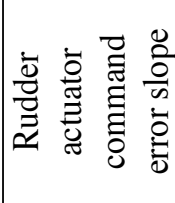 & 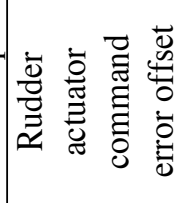 & 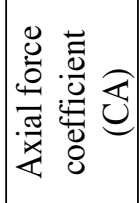 & 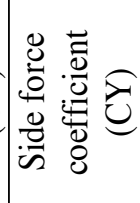 & 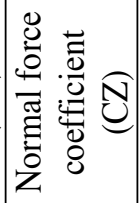 & 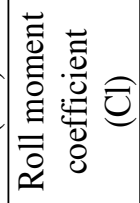 & 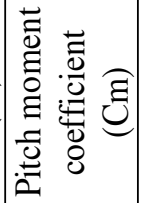 & 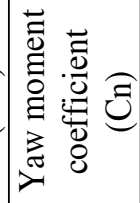 & 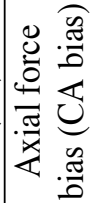 \\
\hline & 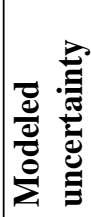 & \multicolumn{2}{|c|}{ 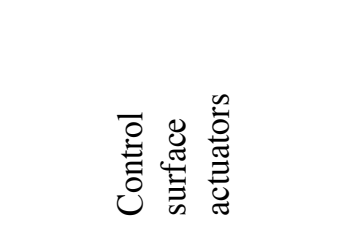 } & \multicolumn{7}{|c|}{ 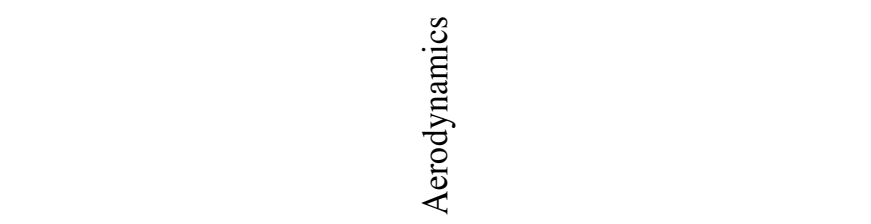 } \\
\hline
\end{tabular}




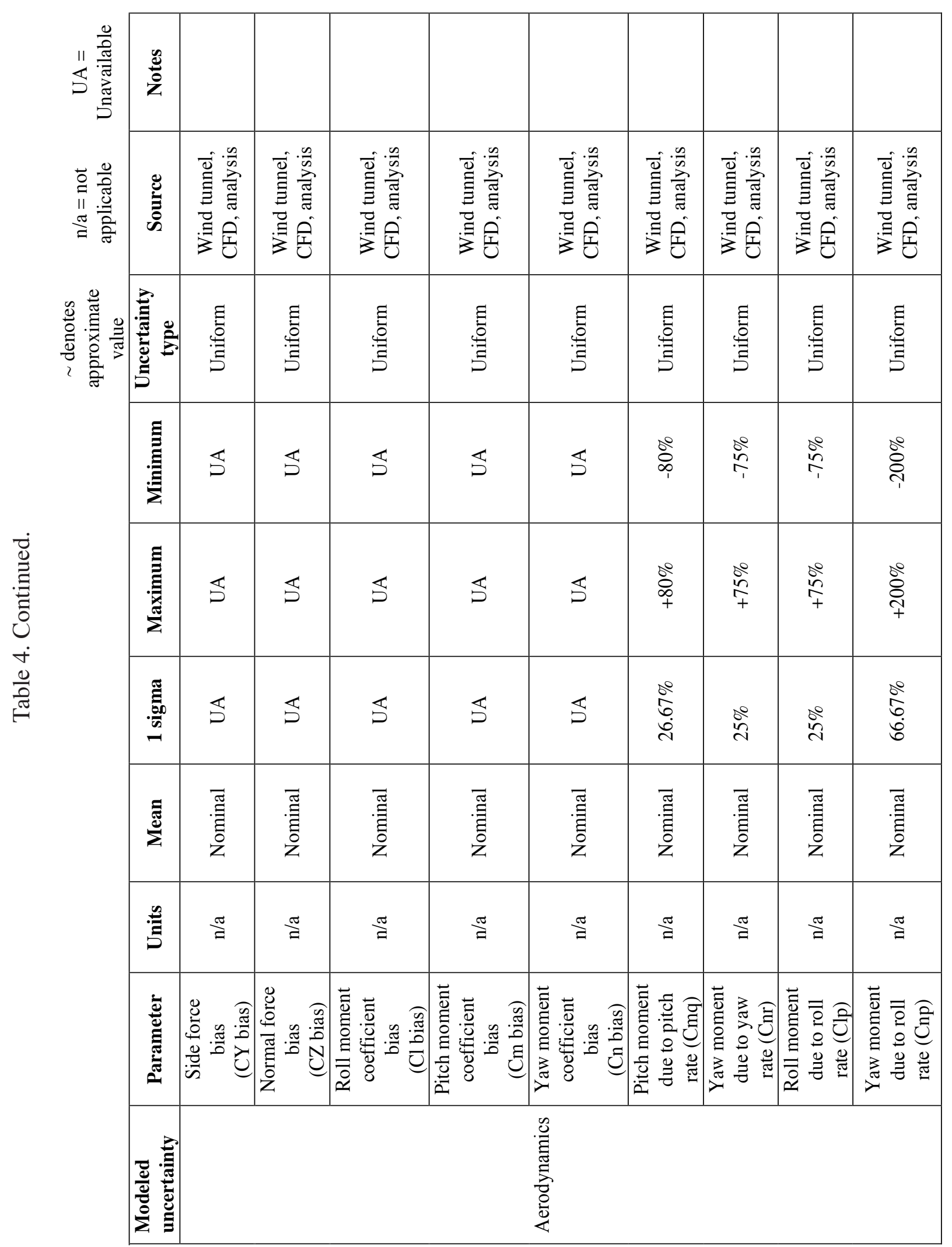




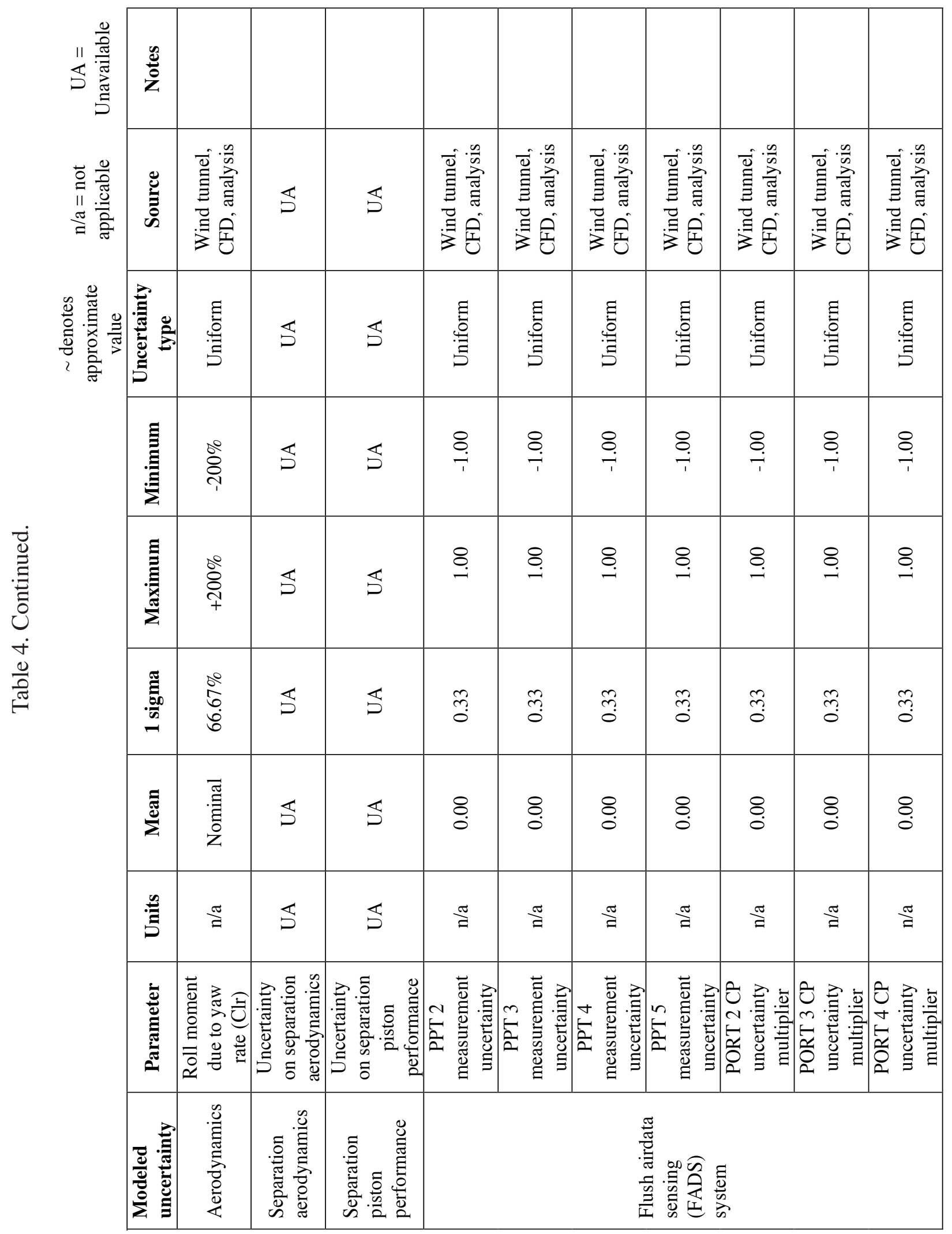




\begin{tabular}{|c|c|c|c|c|c|c|c|c|c|c|c|}
\hline 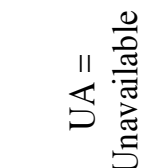 & 苛 & & & & & & & & & & \\
\hline 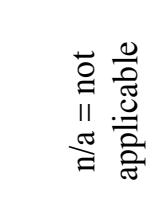 & 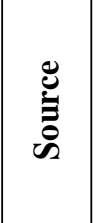 & 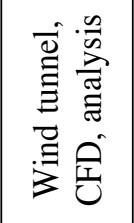 & 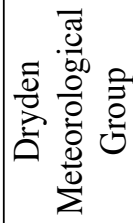 & 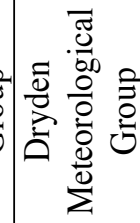 & 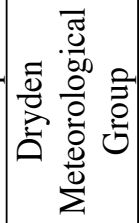 & 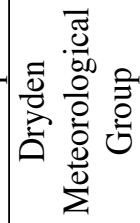 & 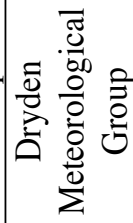 & 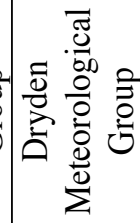 & 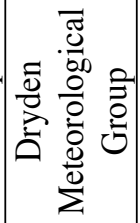 & 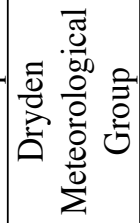 & 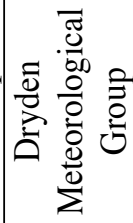 \\
\hline 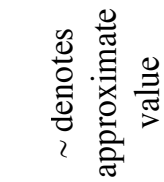 & 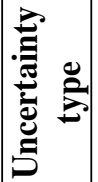 & 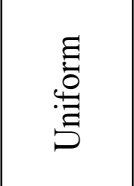 & $\begin{array}{l}\Xi \\
0 \\
.00 \\
\vdots\end{array}$ & 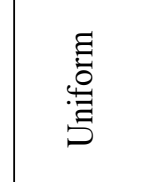 & 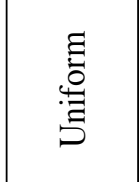 & 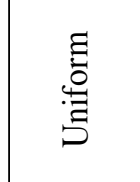 & $\begin{array}{l}\Xi \\
.0 \\
.0 \\
\vdots\end{array}$ & 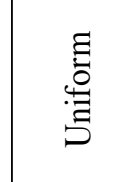 & $\begin{array}{l}\text { E } \\
.00 \\
\text { : }\end{array}$ & 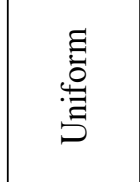 & $\begin{array}{l}\Xi \\
.00 \\
.0 \\
\vdots\end{array}$ \\
\hline & 䒠 & $\frac{8}{1}$ & $\stackrel{8}{\circ}$ & $\begin{array}{l}\text { ते } \\
\text { }\end{array}$ & 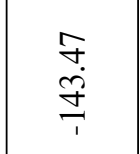 & $\begin{array}{l}\hat{\sigma} \\
\text { İ } \\
\stackrel{1}{1}\end{array}$ & $\begin{array}{l}\text { ते } \\
\stackrel{\circ}{n} \\
\end{array}$ & $\frac{\vartheta}{a}$ & $\begin{array}{l}\stackrel{+}{+} \\
\stackrel{\infty}{+}\end{array}$ & $\stackrel{m}{\stackrel{m}{m}}$ & 志 \\
\hline & 䒠 & $\stackrel{8}{\circ}$ & $\begin{array}{l}\stackrel{8}{ } \\
\text { తI }\end{array}$ & $\begin{array}{l}\infty \\
\stackrel{\infty}{\infty} \\
\infty\end{array}$ & $\begin{array}{l}\mathbb{J} \\
\stackrel{\Theta}{\Xi}\end{array}$ & \begin{tabular}{l}
$n$ \\
\multirow{2}{6}{}
\end{tabular} & 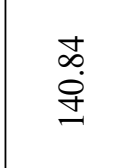 & $\begin{array}{l}\hat{m} \\
\grave{\infty}\end{array}$ & 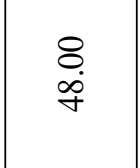 & 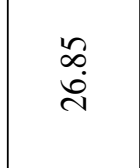 & $\stackrel{+}{\stackrel{+}{d}}$ \\
\hline & 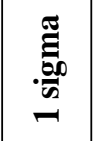 & $\stackrel{m}{0}$ & $\stackrel{\pi}{\Xi}$ & 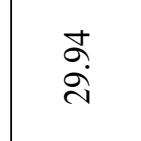 & $\begin{array}{l}\text { ñ } \\
\dot{y}\end{array}$ & $\begin{array}{l}\text { ठ̦. } \\
\text { ه̀ }\end{array}$ & $\begin{array}{l}\bar{n} \\
\stackrel{q}{q}\end{array}$ & & $\begin{array}{l}\dot{O} \\
\stackrel{0}{0}\end{array}$ & $\stackrel{8}{\circ}$ & $\stackrel{\overbrace{}}{\tilde{\sigma}}$ \\
\hline & $\sum^{\bar{\Xi}}$ & $\stackrel{8}{8}$ & 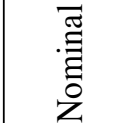 & $\begin{array}{l}\dot{J} \\
\text { aे }\end{array}$ & ă & $\begin{array}{l}0 \\
\stackrel{0}{m}\end{array}$ & $\underset{\substack{\infty \\
\hdashline}}{0}$ & $\underset{\rightarrow}{\stackrel{\longrightarrow}{\top}}$ & $\stackrel{?}{\stackrel{1}{i}}$ & $\frac{\vec{T}}{i}$ & $\underset{i}{\stackrel{+}{i}}$ \\
\hline & $\stackrel{\mathscr{a}}{\stackrel{B}{G}}$ & $\stackrel{\pi}{\Omega}$ & $\begin{array}{l}\tilde{D} \\
\tilde{D}^{0}\end{array}$ & 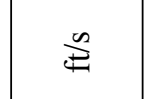 & $\stackrel{\infty}{巳}$ & $\stackrel{\infty}{E}$ & $\stackrel{\infty}{巳}$ & $\sum^{\infty}$ & $\sum^{\infty}$ & $\sum^{\infty}$ & $\sum^{\infty}$ \\
\hline & 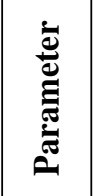 & 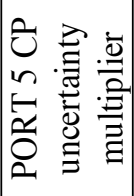 & 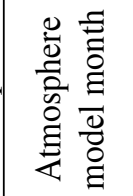 & 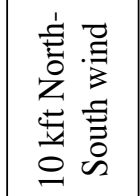 & 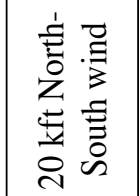 & 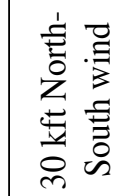 & 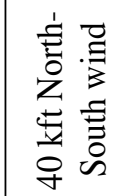 & 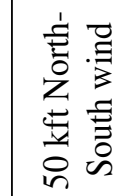 & 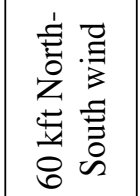 & 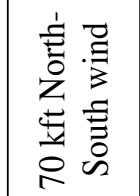 & 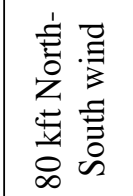 \\
\hline & 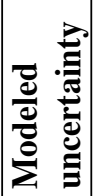 & 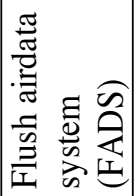 & 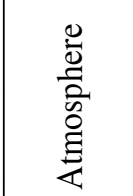 & \multicolumn{8}{|c|}{$\stackrel{0}{0}$} \\
\hline
\end{tabular}




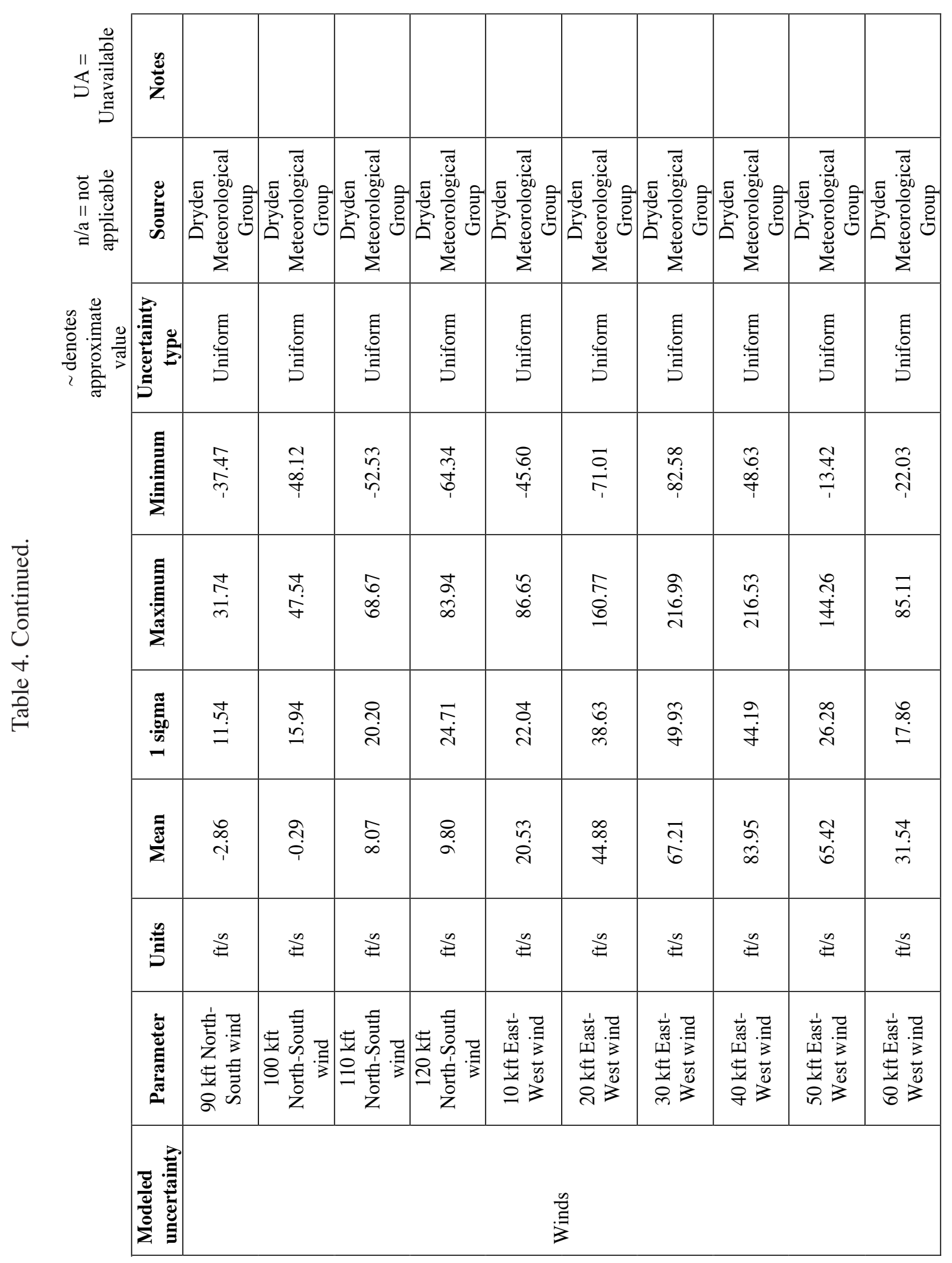




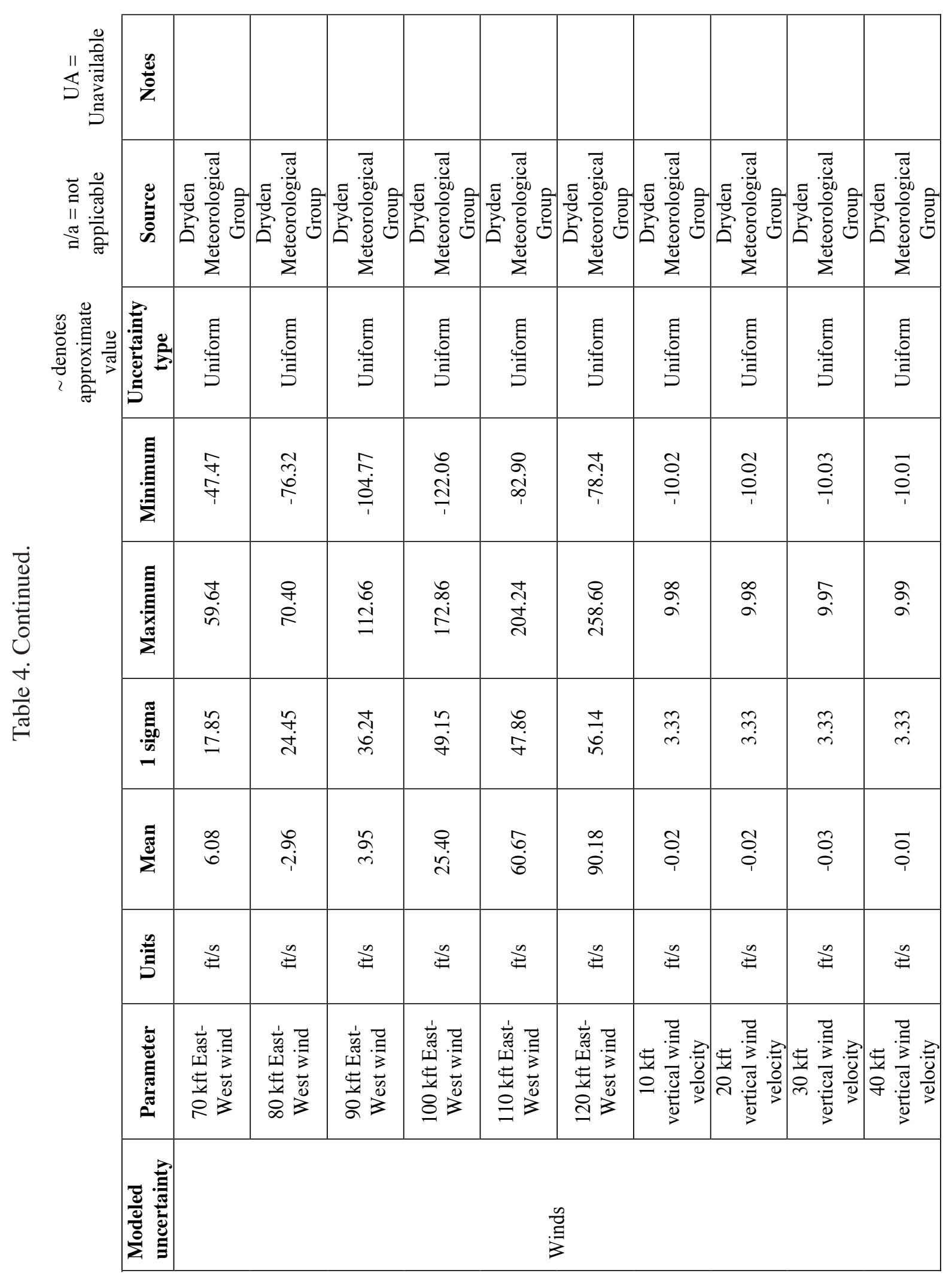




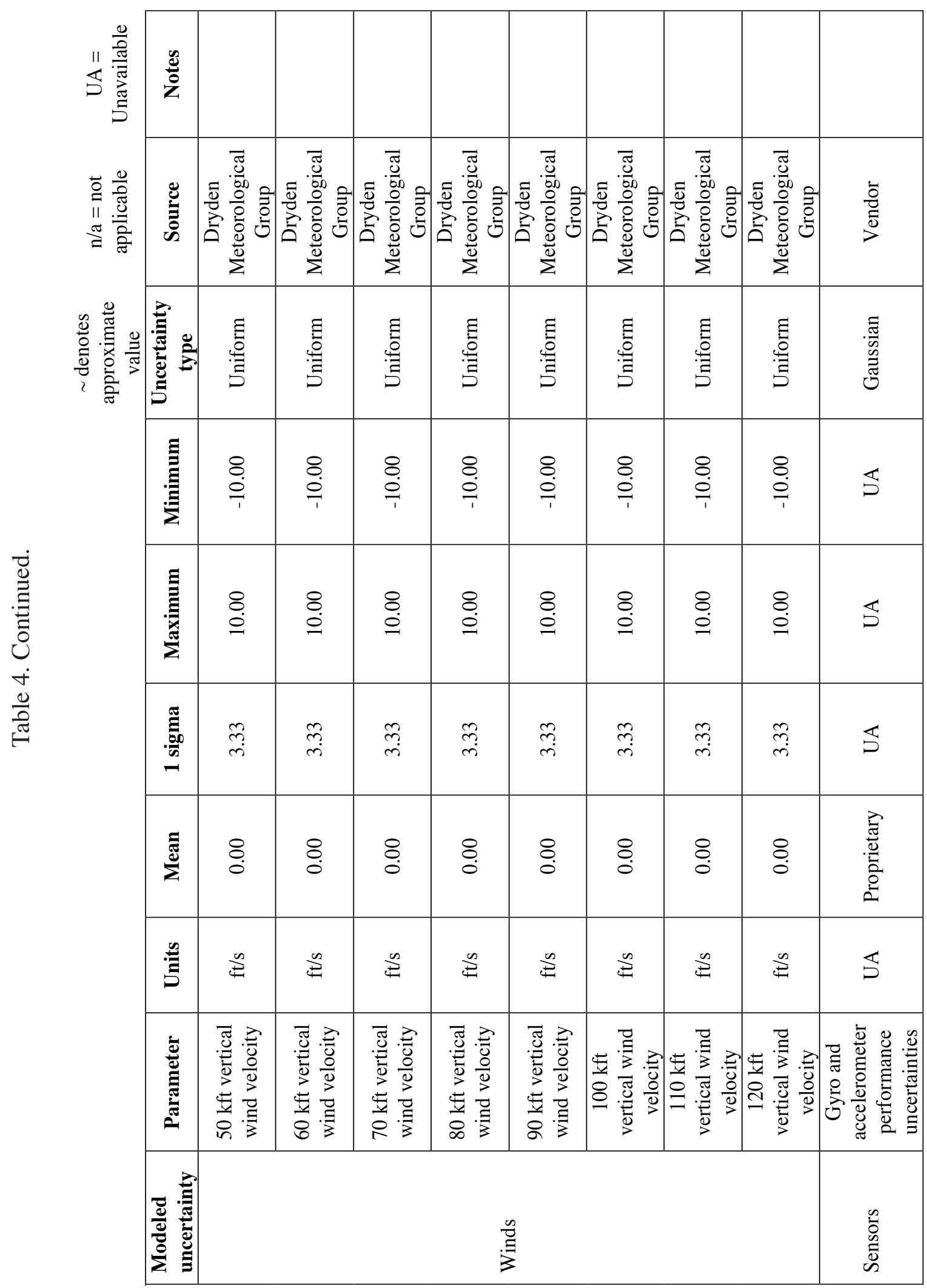




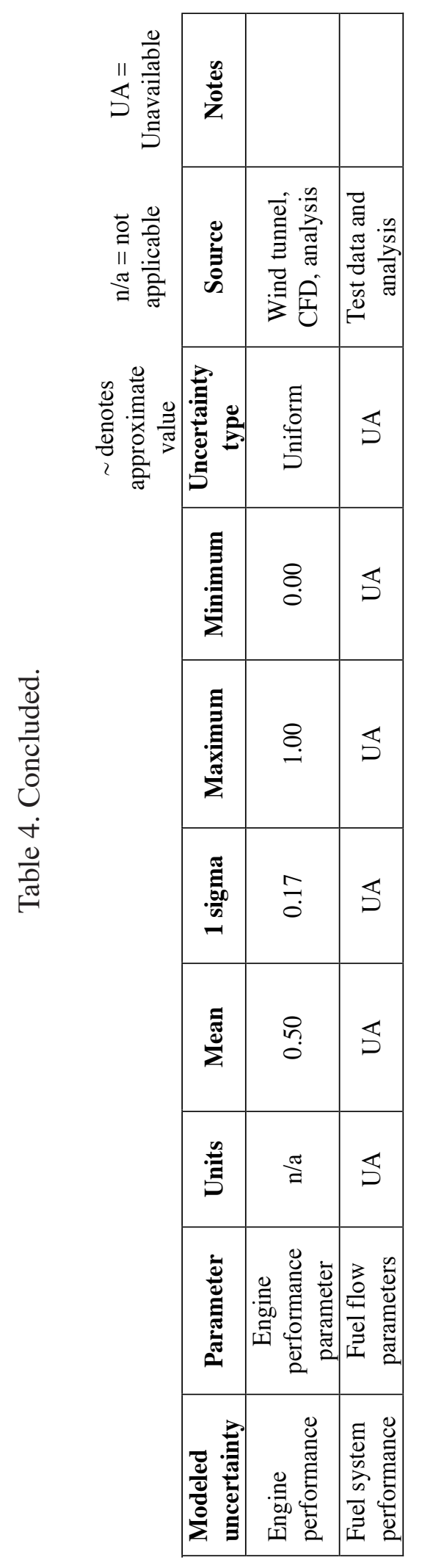


Table 5. Validation test selection criteria.

[X denotes a parameter was selected for a maximum or minimum value]

\begin{tabular}{|c|c|c|c|c|c|}
\hline Parameter & Separation & Engine Test & $\begin{array}{c}\text { Recovery } \\
\text { Maneuver }\end{array}$ & Descent & Splashpoint \\
\hline $\begin{array}{l}\text { Angle of } \\
\text { attack }\end{array}$ & $\mathrm{X}$ & $X$ & $X$ & $\mathrm{X}$ & \\
\hline $\begin{array}{l}\text { Angle of } \\
\text { sideslip }\end{array}$ & $\mathrm{X}$ & $\mathrm{X}$ & & $\mathrm{X}$ & \\
\hline $\begin{array}{l}\text { Left wing } \\
\text { deflection }\end{array}$ & $\mathrm{X}$ & $\mathrm{X}$ & & $X$ & \\
\hline $\begin{array}{l}\text { Right wing } \\
\text { deflection }\end{array}$ & $\mathrm{X}$ & $\mathrm{X}$ & & $\mathrm{X}$ & \\
\hline $\begin{array}{l}\text { Right rudder } \\
\text { deflection }\end{array}$ & $\mathrm{X}$ & $\mathrm{X}$ & & $\mathrm{X}$ & \\
\hline $\begin{array}{l}\text { Flight path } \\
\text { angle }\end{array}$ & & & $\mathrm{X}$ & $\mathrm{X}$ & \\
\hline Altitude & & $\mathrm{X}$ & & & \\
\hline Altitude error & & & $X$ & $\mathrm{X}$ & $\mathrm{X}$ \\
\hline Mach & & $X$ & & $X$ & $\mathrm{X}$ \\
\hline $\begin{array}{l}\text { Normal } \\
\text { acceleration }\end{array}$ & $\mathrm{X}$ & $\mathrm{X}$ & $\mathrm{X}$ & $\mathrm{X}$ & \\
\hline Roll rate & $X$ & $X$ & & & \\
\hline Pitch rate & $X$ & $X$ & & & \\
\hline $\begin{array}{l}\text { Dynamic } \\
\text { pressure }\end{array}$ & & $\mathrm{X}$ & $\mathrm{X}$ & $\mathrm{X}$ & $\mathrm{X}$ \\
\hline Yaw rate & $\mathrm{X}$ & $X$ & & & \\
\hline Phi & $\mathrm{X}$ & $X$ & & $X$ & \\
\hline Theta & $\mathrm{X}$ & & $X$ & $X$ & \\
\hline Time & & & & & $X$ \\
\hline
\end{tabular}




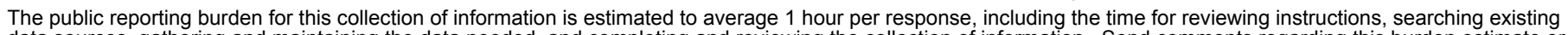
data sources, gathering and maintaining the data needed, and completing and reviewing the collection of information. Send comments regarding this burden estimate or any other aspect of this collection of information, including suggestions for reducing this burden, to Department of Defense, Washington Headquarters Services,

Directorate for Information Operations and Reports (0704-0188), 1215 Jefferson Davis Highway, Suite 1204, Arlington, VA 22202-4302. Respondents should be aware that notwithstanding any other provision of law, no person shall be subject to any penalty for failing to comply with a collection of information if it does not display a currently valid OMB control number.

PLEASE DO NOT RETURN YOUR FORM TO THE ABOVE ADDRESS
1. REPORT DATE (DD-MM-YYYY)
2. REPORT TYPE
3. DATES COVERED (From - To)

01-12-2007

Technical Memorandum

4. TITLE AND SUBTITLE

The X-43A Six Degree of Freedom Monte Carlo Analysis

5a. CONTRACT NUMBER

5b. GRANT NUMBER

5c. PROGRAM ELEMENT NUMBER

6. AUTHOR(S)

Baumann, Ethan; Bahm, Catherine; Strovers, Brian; Beck, Roger; Richard, Michael 5d. PROJECT NUMBER

5e. TASK NUMBER

5f. WORK UNIT NUMBER

7. PERFORMING ORGANIZATION NAME(S) AND ADDRESS(ES)

NASA Dryden Flight Research Center

P.O. Box 273

Edwards, California 93523-0273

H-2683

9. SPONSORING/MONITORING AGENCY NAME(S) AND ADDRESS(ES)

National Aeronautics and Space Administration

Washington, DC 20546-0001 REPORT NUMBER

NASA
8. PERFORMING ORGANIZATION

10. SPONSORING/MONITOR'S ACRONYM(S)

11. SPONSORING/MONITORING REPORT NUMBER

NASA/TM-2007-214630

12. DISTRIBUTION/AVAILABILITY STATEMENT

Unclassified -- Unlimited

Subject Category 05

Availability: NASA CASI (301) 621-0390

Distribution: Standard

\section{SUPPLEMENTARY NOTES}

Baumann, Bahm, and Strovers, Dryden Flight Research Center; Beck, Analytical Mechanics Associates, Inc.; Richard, Rockwell Collins

\section{ABSTRACT}

This report provides an overview of the Hyper-X research vehicle Monte Carlo analysis conducted with the six-degree-of-freedom simulation. The methodology and model uncertainties used for the Monte Carlo analysis are presented as permitted. In addition, the process used to select hardware validation test cases from the Monte Carlo data is described. The preflight Monte Carlo analysis indicated that the X-43A control system was robust to the preflight uncertainties and provided the Hyper-X project an important indication that the vehicle would likely be successful in accomplishing the mission objectives. The X-43A in-flight performance is compared to the preflight Monte Carlo predictions and shown to exceed the Monte Carlo bounds in several instances. Possible modeling shortfalls are presented that may account for these discrepancies. The flight control laws and guidance algorithms were robust enough as a result of the preflight Monte Carlo analysis that the unexpected in-flight performance did not have undue consequences. Modeling and Monte Carlo analysis lessons learned are presented.

\section{SUBJECT TERMS}

Hardware in the loop validation testing, Hyper-X, Monte Carlo analysis, Sensitivity analysis, X-43A

16. SECURITY CLASSIFICATION OF:

\begin{tabular}{c|c|c|}
\hline a. REPORT & b. ABSTRACT & c. THIS PAGE \\
$\mathrm{U}$ & $\mathrm{U}$ & $\mathrm{U}$ \\
\hline
\end{tabular}

\section{LIMITATION OF} ABSTRACT
18. NUMBER OF PAGES 19b. NAME OF RESPONSIBLE PERSON

STI Help Desk (email: help@sti.nasa.gov) 19b. TELEPHONE NUMBER (Include area code)
$\mathrm{U}$

50 